\title{
Chapter 5 \\ Design and Analysis of a Whole-Body Noncontact Electromagnetic Subthreshold Stimulation Device with Field Modulation Targeting Nonspecific Neuropathic Pain
}

\author{
Sergey Makarov, Gene Bogdanov, Gregory Noetscher, William Appleyard, \\ Reinhold Ludwig, Juho Joutsa, and Zhi-De Deng
}

\subsection{Introduction}

Pain is distinguished by duration as acute (less than 6 weeks), subacute (6-12 weeks), and chronic (12 weeks or more) pain. Approximately 100 million US adults suffer from common chronic pain conditions, more than the number affected by heart disease, diabetes, and cancer combined [1]. The economic cost of chronic pain in adults, including health care expenses and lost productivity, is \$560-630 billion annually

\footnotetext{
S. Makarov $(\bowtie)$

Massachusetts General Hospital, Boston, MA, USA

Worcester Polytechnic Institute, Worcester, MA, USA

e-mail: makarov@wpi.edu

G. Bogdanov · W. Appleyard · R. Ludwig

ECE Department, Worcester Polytechnic Inst, Worcester, MA, USA

G. Noetscher

Worcester Polytechnic Institute, Worcester, MA, USA

J. Joutsa

Athinoula A. Martinos Center for Biomedical Imaging, Massachusetts General Hospital,

Harvard Medical School, Charlestown, MA, USA

Department of Neurology, University of Turku, Turku, Finland

Division of Clinical Neurosciences, Turku University Hospital, Turku, Finland
}

Z.-D. Deng

Noninvasive Neuromodulation Unit, Experimental Therapeutics \& Pathophysiology Branch, National Institutes of Mental Health, NIH, Bethesda, MD, USA 
[1]. Seven in ten Americans feel that pain research and management should be one of the medical community's top few priorities (16\%) or a high priority (55\%) [2].

One form of chronic pain is nociceptive pain, which is the normal response to injury of tissues such as muscles, visceral organs, joints, or bones. Another form is neuropathic pain, which involves dysfunction of (i) the peripheral nervous system (PNS) or (ii) the central nervous system (CNS). The latter case is amplification and generation of pain within the CNS itself due to distorted sensory processing, malfunctioning of pain-inhibitory mechanisms, and enhancing pain-facilitatory mechanisms [3-6]. An example is psychogenic pain, which does not usually have a physical origin [7, 8]. Highly prevalent symptoms in chronic pain are depression and anxiety [7-11], which are reported by more than $50 \%$ of patients with chronic pain [9]. Pain and depression may create a vicious cycle in which pain worsens depression and vice versa [10].

Low back pain, either acute or chronic, dominates other pain types [7] and affects about $80-84 \%$ of the population at least once at some point in life [12-14]. In the US Armed Services alone, low back pain was the primary diagnosis for more than seven million ambulatory care visits between 2000 and 2009 [15]. Current estimates are that approximately $25 \%$ of people with acute low back pain experience recurrent episodes, while 7-10\% progress to a chronic state [15] and can experience significant physical, psychological, and social sequelae that affect their long-term functioning and quality of life [16]. According to [11], 70\% of subjects with chronic low back pain report fatigue and $18 \%$ report depression. According to [17], 59\% of the patients with chronic low back pain report poor sleep.

Chronic low back pain accounts for $22 \%$ of all chronic pain cases and for $35 \%$ of most persistent pain sites [7]. The classification of low back pain is complicated by the varying presentation and complex nature of pain [14]. The most common diffuse neuropathic pain without radiating beyond the buttocks is classified as nonspecific low back pain [14], which makes up $60 \%$ of individuals suffering from chronic low back pain [18].

The initial treatment for acute nonspecific low back pain is conservative, including nonopioid analgesics (acetaminophen, aspirin), nonsteroidal anti-inflammatory drugs (ibuprofen, ketoprofen), physiotherapy, dynamic strengthening exercises, thermotherapy, and, if necessary, a short course of muscle relaxants [13, 14]. Further, conservative methods include traction treatment, manual therapy, and transcutaneous electrical nerve stimulation (TENS) [14]. A commonly prescribed treatment for chronic pain is opioids (codeine, oxycodone, hydrocodone, and morphine) $[13,19]$. The use of opioids is controversial due to severe addiction and misuse $[13,15,16,20,21]$. It is argued that chronic use of opioids is detrimental to people with back pain because they can aggravate depression, leading to a worsening of the pain [13]. Whenever possible, opioid medications in chronic noncancer pain should be avoided [20].

TENS is a common drug-free alternative treatment technique that stimulates selected sensory nerves and muscles via electrodes placed on the skin over the painful area [22-28]. The electrodes inject electric currents and, most importantly, electric fields into body. The theory is that the local electric field stimulation can modify 
both cause and perception of chronic pain. A number of systematic reviews of the effect of TENS on various painful conditions, such as labor pain, rheumatoid arthritis, phantom limb pain, and chronic lower back pain, are available [22, 24-28]. However, these reviews indicate that most controlled randomized clinical trials failed to show significant effects of the existing small-scale TENS systems with a strongly localized electric field distribution.

This design-based study is driven by the limitations of TENS. We introduce a conceptually different electromagnetic stimulation device. Instead of local highintensity and suprathreshold TENS, we suggest to stimulate the PNS and muscular system of the entire lower body in a noncontact, patient-friendly way. At the same time, we suggest to use low or subthreshold power levels. In other words, we propose mild yet more broad electromagnetic treatment, potentially beneficial for nonspecific chronic pain. The proposed device $[29,30]$ would primarily affect peripheral nerves, the spinal cord, muscles, joints, and bone. Simultaneously, it could influence the somatosensory cortex via many affected pathways, in line with the modern concept of central control of pain [8]. Based on the numbers cited above [7, 14, 18], we can estimate that some $14 \%$ of all chronic pain cases might be subject to the proposed alternative treatment.

The text is organized as follows. Section 5.2 describes a theoretical device model, specifies the field distribution within the resonator, and describes hardware design, test, and functionality, including semiautomatic operation/tuning and representative continuous run times. Section 5.3 provides computational results for the electric field distribution within the body obtained via two independent numerical methods. Section 5.4 discusses possible device modifications, as well as potential application scenarios. Section 5.5 concludes the chapter.

\subsection{Materials and Methods}

\subsubsection{Suprathreshold Versus Subthreshold Stimulation}

The vast majority of transcutaneous electrical nerve stimulation (TENS) devices $[14,22-28]$ today are suprathreshold. They excite local currents/electric fields that are strong enough to produce an action potential in peripheral axons assembled in bundles of sensory nerve fibers. A case in point is a small pulsed-current InTENSity ${ }^{\mathrm{TM}}$ Twin Stim ${ }^{\circ}$ III device [31] similar to that shown in Fig. 5.1a [32], intended for home use. It creates a prominent zapping sensation when the electrodes are connected to the lower back. The majority of PEMF (pulsed electromagnetic field) devices operate in a similar fashion.

Alternatively, a continuous current injection with a more powerful stationary device may be employed by chiropractors as shown in Fig. 5.1b [33]. When connected to the lower back, it creates a rather strong burning sensation. The electric field may also be injected via a noncontact induction coil $[34,35]$ as in Fig. 5.1c. 

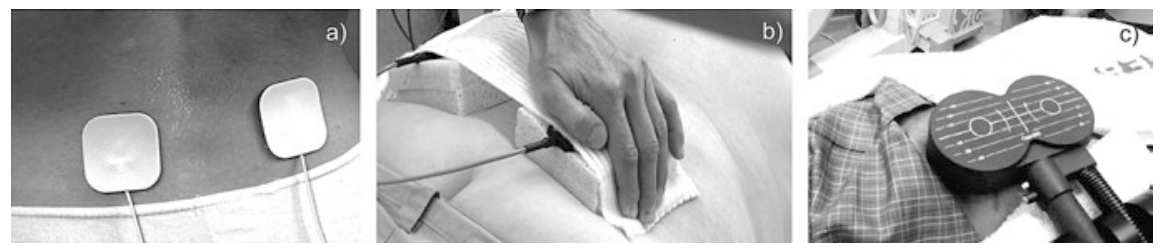

Fig. 5.1 (a) Portable pulsed-current TENS (or PEMF) device from National Health Service (NHS) England website [32]. (b) Stationary continuous-current TENS device with sponge electrodes for low back pain treatment in Hannover, Germany [33]. (c) Induction coil-based peripheral neuropathic pain stimulation for low back pain treatment $[34,35]$

Although a broader coverage with many electrodes is now possible, local suprathreshold effects still dominate.

With respect to treatment-persistent depression, only three nonpharmacological therapies have been approved by the FDA to date; all of them are electromagnetic and suprathreshold: transcranial magnetic stimulation [36], vagus nerve stimulation [37], and electroconvulsive therapy [38].

Subthreshold refers to a low-power electromagnetic stimulation that is too small to elicit action potentials. However, it still alters the axonal membrane potential [39]. This effect accumulates and maximizes toward axon terminals, i.e., synapses [39]. It is synaptic efficacy (or natural neurotransmission efficacy) that is altered and enhanced by the subthreshold stimulation [39]. In a chain of neurons, this stimulation could cause an incremental relay effect, which may further enhance neuronal network activity [39]. The theory of subthreshold stimulation [39-42] has been developed in application to transcranial current stimulation [39-47]. Lowfield magnetic stimulation of depression is an active area of research [48-54]. The subthreshold technique is also a modern research direction in spinal cord stimulation [55-59], as it eliminates noxious and off-target paresthesia, while being efficient, as well as in vagus [60], occipital [61], proximal [62], and parasympathetic [63] nerve stimulation, and in neuromuscular stimulation [64]. Electrocutaneous subthreshold stimulation has been found to improve sleep and reduce reactive anxiety/depression [65].

\subsubsection{Concept of the Magnetic Stimulator. Two-Dimensional Analytical Solution for Solenoidal E-Field}

Figure 5.2 shows the anticipated device concept. An external, uniform, rotating (or circularly-polarized) magnetic flux density $\mathbf{B}$ with amplitude $B_{0}$ is created in the transverse plane around a tissue volume, depicted in Fig. 5.2a. By Faraday's law of induction, this field excites an axial, rotating solenoidal electric field $\mathbf{E}$ in free space or in a tissue volume, which is expressed in terms of the magnetic vector potential $\mathbf{A}$, 
a)

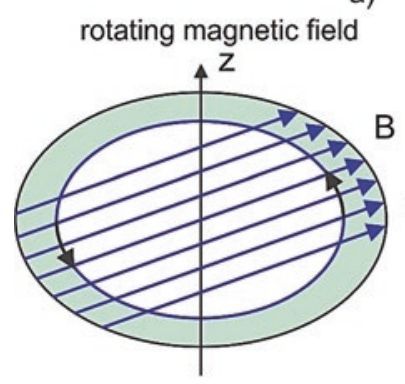

rotating electric field

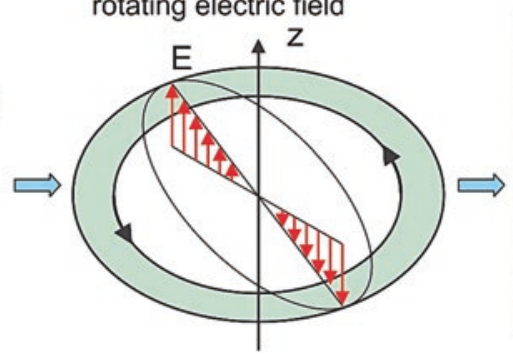

b)

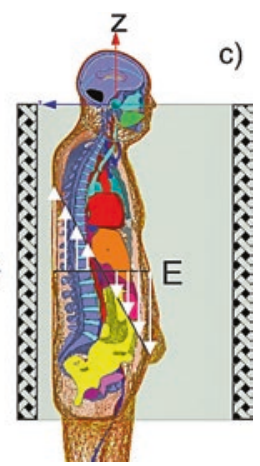

Fig. 5.2 Concept of non-invasive electric field excitation via the induction mechanism. A rotating magnetic field shown in (a) excites the rotating electric field within the conductor (b) and within the body (c), respectively

$$
\boldsymbol{E}=-\partial \boldsymbol{A} / \partial t
$$

as shown in Fig. 5.2b; we set $\mathbf{B}=\nabla \times \mathbf{A}$. Thus, when a biological body is placed into this volume, a significant noninvasively excited electric field in the axial direction will appear parallel to the major peripheral nerves, spinal cord, long bones, major arteries, veins, and other structures. This is in contrast to a solenoidal coil wound around the body creating electric fields and currents in the less desirable transverse plane.

The rotational character of the field also assures that not only one body cross section (e.g., coronal or sagittal) will be subject to the electric field excitation, but the entire body volume.

In the ideal, two-dimensional case and for any conducting target with a strict cylindrical symmetry placed into the device, either homogeneous or not, the corresponding two-dimensional problem, shown in Fig. 5.2a, b, will have an exact analytical solution in the quasi-static (or eddy current) approximation. The electric field within the target is given by [66].

$$
\begin{gathered}
E_{x}=0, \quad E_{y}=0, \quad E_{z}=\omega B_{0} r \cos (\omega t-\phi) \\
\boldsymbol{J}=\sigma \boldsymbol{E}
\end{gathered}
$$

where $r$ is the radial distance from the coil axis in cylindrical coordinates, $\omega$ is the angular frequency, $\phi$ is an arbitrary phase, $\boldsymbol{J}$ is induced current density, and $\sigma$ is the (local) medium conductivity which is either constant or obeys cylindrical symmetry. Although Eqs. (5.2) and (5.3) might be used to roughly estimate the electric field in the body based on a cylindrically symmetric assumption, its actual value will deviate as shown below. 


\subsubsection{Three-Dimensional Coil Resonator Design. Solenoidal E-Field}

The external rotating magnetic flux density $\mathbf{B}$ is created using a volumetric resonator in the form of a low-pass birdcage coil. Resonators of this type (called "birdcage coils") are routinely used as MRI radio frequency (RF) coils [67, 68], but for a completely different purpose, namely atomic spin excitation and RF signal acquisition. The resonant frequency in this application is very high, typically $64 \mathrm{MHz}$ (for 1.5 T magnets) or higher. For our purpose, we decided to reconstruct that design for a much lower frequency band of $100 \mathrm{kHz}$ or less. In particular, the band of $10 \mathrm{kHz}$ has recently demonstrated great promise for spinal cord stimulation for back and leg chronic pain management [55-59, 69-77] with and without previous back surgeries [70, 72], and is utilized by TENS [78]. In addition to superior pain relief, the $10 \mathrm{kHz}$ band may provide long-term improvements in quality of life and functionality for subjects with chronic low back and leg pain [77]. On the other hand, a wider band of 4-30 kHz has been used for polyneuropathy (a general degeneration of peripheral nerves that spreads toward the center of the body) electrostimulation treatment [79-82].

We chose the birdcage coil because it can produce a very homogeneous B-field in the transverse plane, and because it can produce a circularly polarized B-field. These features relax the requirements for accurate patient positioning relative to the coil. The patient has significant freedom of movement transversely within the coil, including freedom of rotation (thanks to circular polarization). This should enhance patient comfort and permit long treatment sessions.

The resonator concept will allow for an arbitrary "tonic" modulation [30] of the carrier frequency, which was found to beneficially address the variable nature of chronic pain across different patients [76]. This modulation can be either open- or closed-loop (e.g., a single-channel EEG signal fed back to the modulator).

When the resonant frequency becomes low as in the present case, the standard RF birdcage coil will possess very low inductance $L$. Tuning such a coil toward resonance at low frequencies would require large capacitance $C$. This, however, means a low $Q$-factor (quality factor $Q=\sqrt{L / C} / R$ is the "gain" of the series resonator) and higher costs, as well as higher fabrication complexity [83,84], and will restrict the use of the conventional birdcage coil to frequencies above at least a few megahertz. Different methods to overcome this difficulty have been suggested [8388], but they are all limited to small-size coils.

Our design described in the subsequent patent application [29] utilizes a unique large-scale low-pass birdcage coil topology with an intentionally very large number (144) of long rungs (boosting inductance) and bridging capacitors seen in Figs. 5.6 and 5.7. After this point, the improvement in adding more rungs is small. Several other reasons for the number of rungs include:

- To distribute the required capacitors uniformly around the coil circumference

- To improve the mechanical stiffness of this self-supporting coil structure 
- To reduce rung tube diameter, simplifying assembly

- To facilitate direct drive of the coil at a single rung (for each mode). The equivalent parallel resistance at resonance was significantly above $50 \mathrm{ohms}$ for the 144 rung configuration, permitting the use of capacitive-only matching networks. Later in the development process, we decided not to use direct drive, but the option remains

However, we are not claiming that the particular number of rungs we used is optimal. All the coil geometrical parameters (number of rungs, rung and end ring tube diameters, coil length and diameter) are subject to optimization during design and construction of the next prototype. We may even consider switching to a fundamentally different coil winding design, such a saddle coil. That said, any optimization is not expected to dramatically improve the coil's B-field. Improvements up to $20 \%$ may be possible (slightly more if the coil is made smaller).

Along with this, we employ carefully designed inductive power coupling. The inductive coupling blocks DC and acts as a balun (balanced-unbalanced transformer). This is useful in terms of both circuit design (we avoid having to install a transformer) and safety concerns (no direct path from the AC to the coil). It also allows adjusting the load resistance at resonance. Inductive coupling perturbs the current distribution in the coil significantly less than directly driving an individual rung. As a result, the resonator possesses a superior quality factor of approximately 300 [30]. Therefore, we may achieve any desired electric field levels of up to $50-100 \mathrm{~V} / \mathrm{m}$ within the lower body due to the resonance effect and still use standard power electronics equipment.

A computational model of a particular resonator constructed in this study is shown in Fig. 5.3a with the electric current distribution to scale. The coil has a diameter of $0.94 \mathrm{~m}$ and a length of $1.10 \mathrm{~m}$; the coil resonates at $100 \mathrm{kHz}$ or at $145 \mathrm{kHz}$ depending on the values of the bridging capacitors. The coil consists of two rings (top and bottom) joined via multiple straight rungs, each bridged with a lumped capacitor at its center. The capacitors control the coil's resonant frequency. The resonating coil is fed via two lumped ports in quadrature, or using inductive coupling with two loops in quadrature as explained below.

From the modeling point of view, the resonant electric current in both rings at any fixed time instant behaves like a full period of a sine function of polar angle $\varphi$. This ring current distribution is shown in Fig. 5.3a. As time progresses, the ring current distribution shown in Fig. 5.3a rotates with angular frequency $\omega$. As a result, the time-domain ring current $i(t, \varphi)$ in the top and bottom rings can be expressed in the form

$$
i(t, \varphi)= \pm I_{0} \cos (\omega t-\varphi+\pi / 2), \varphi \in 0,2 \pi
$$

where $I_{0}$ is the current amplitude determined by the excitation power and by the quality factor (or the "gain") of the resonator.

The AC current in each rung shown in Fig. 5.3a does not change along its length. Simultaneously, at any fixed time instant, it also varies from rung to rung as a har- 
monic function of the polar angle $\varphi$ with the full period corresponding to the ring circumference. This rung current distribution is shown in Fig. 5.3a. As time progresses, the rung current distribution shown in Fig. 5.3a also rotates with angular frequency $\omega$. Each individual time-domain rung current density $j(t, \varphi)$ can be expressed in the form

$$
j(t, \varphi)=\frac{I_{0}}{F} \cos (\varphi+\omega t), \quad F=\frac{1}{2} \sum_{m=0}^{\frac{N}{2}-1} \sin \left(\frac{2 \pi m}{N}\right), \quad \varphi \in 0,2 \pi
$$

where $N$ is the total number of rungs. This form obeys the current conservation law, or Kirchhoff's Current Law (KCL), at every ring-rung junction.

The useful current, which creates a nearly constant horizontal rotating magnetic field $B_{r}$ with amplitude $B_{0}$ and axial rotating electric field $E_{z}$ according to Eq. (5.2), is the rung current density $j(t, \varphi)$. Contributions of each rung add up in a constructive manner. The ring current, on the other hand, does not contribute to the axial (or vertical) electric field, $E_{z}$. However, it may create a strong transverse electric field very close to the rings.

It should be pointed out that Eqs. (5.4) and (5.5) describe the rotating current behavior, which is a combination of two elementary resonant modes. Each elementary mode does not rotate and appears as depicted in Fig. 5.3a. However, when excited in quadrature (with a 90 degree phase shift and a 90 degree excitation offset along the coil circumference), both modes combine to create the current distribution given by Eqs. (5.4) and (5.5) and the associated rotating electric field. The rotation phenomenon enables us to treat the entire body and not merely a singular component or region.

\subsubsection{Solenoidal Electric Field Distribution with and without a Simple Conducting Object}

Figure 5.3b-d shows the resulting electric field distribution in the coil (coronal plane) when the current amplitude $I_{0}=1$ ampere in either ring given by Eq. (5.4). The results are given for one resonant mode, as shown in Fig. 5.3a. Due to linearity, this result can simply be scaled for other excitation levels. Accurate field computations have been performed with the fast multipole method described in [89]. The magnitude of the axial component $E_{z}$ in $\mathrm{V} / \mathrm{m}$ for an empty coil is shown in Fig. 5.3b. The electric field is indeed zero at the coil's center.

When a conducting object representing a load is inserted into the coil, the field distribution changes. Figure 5.3c shows the distribution when a conducting cylinder with a diameter of $0.4 \mathrm{~m}$ and a length of $1 \mathrm{~m}$ is inserted into the coil along its axis. The particular conductivity value $\sigma$ does not matter since only the conductivity contrast, $\left(\sigma-\sigma_{\text {air }}\right) /\left(\sigma+\sigma_{\text {air }}\right)$, is present in the solution [66]. This value is always unity since $\sigma_{\text {air }}=0$. 


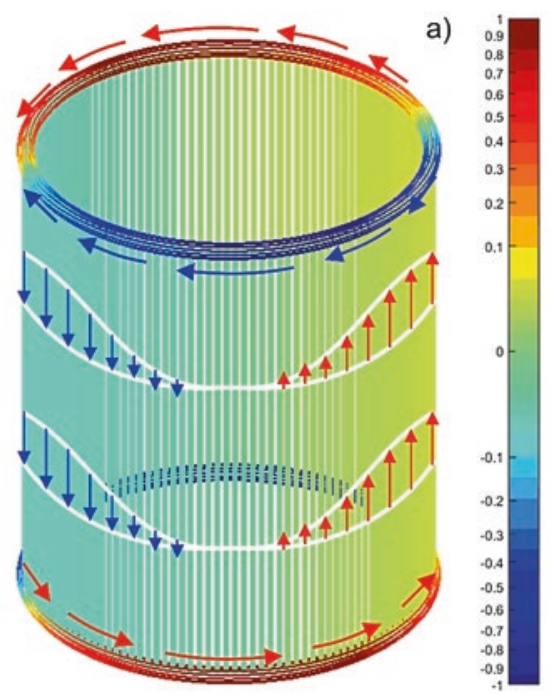

b)

c)

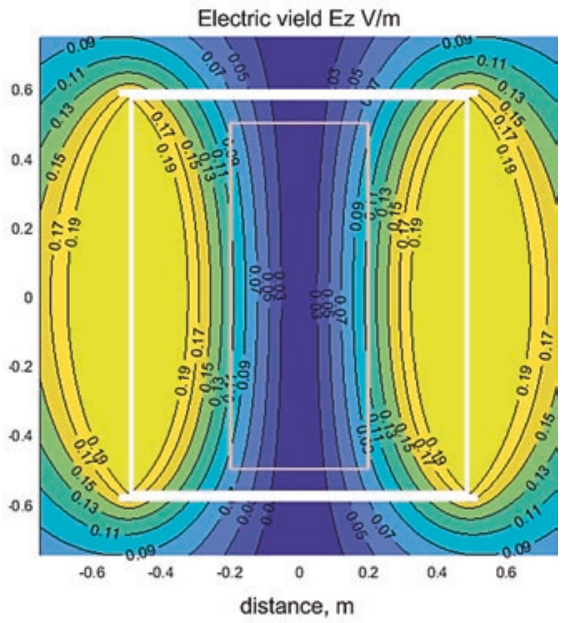

d)
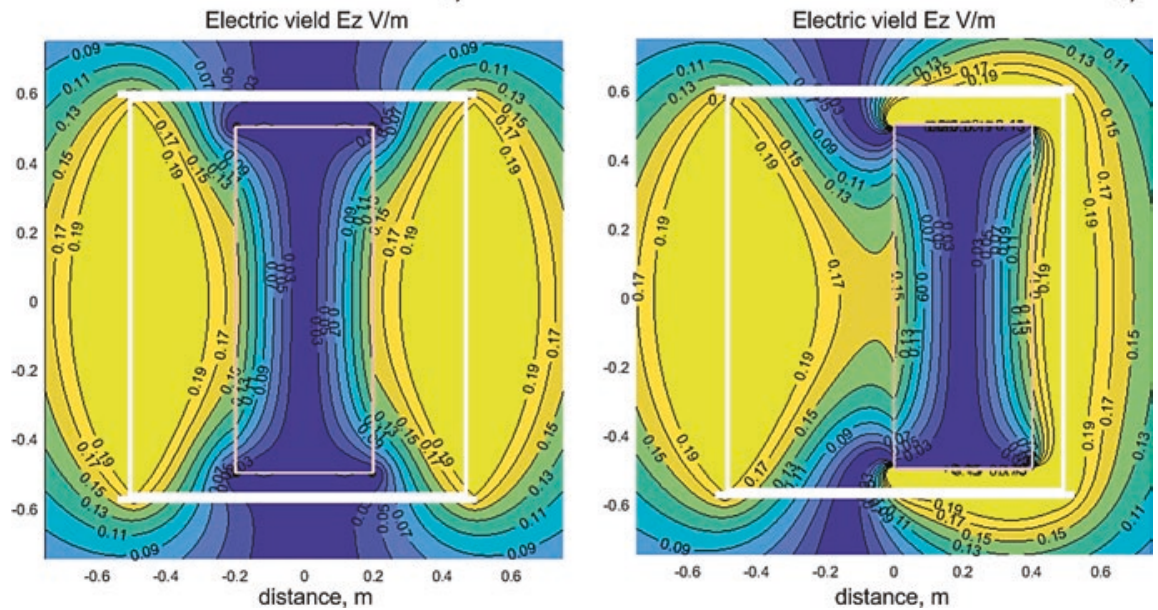

Fig. 5.3 Current distribution in the coil resonator and the associated solenoidal electric field created by the coil when the ring current amplitude is $1 \mathrm{~A}$ for one resonant mode. (a) Electric current distribution in the coil along with the current color bar to scale; (b) Magnitude of the vertical electric field $E_{z}$ in $\mathrm{V} / \mathrm{m}$ for an empty coil in the coronal plane; (c) Magnitude of the vertical electric field $E_{z}$ in V/m for the coil with a coaxial conducting cylinder $0.4 \times 1 \mathrm{~m}$ inside; (d) Magnitude of the vertical electric field $E_{z}$ in $\mathrm{V} / \mathrm{m}$ for the coil with a conducting cylinder $0.4 \times 1 \mathrm{~m}$ shifted in the transverse plane inside

An interesting and useful effect is observed in Fig. 5.3c: we see a "pulling" of the electric field into the cylinder close to the coil center. This is due to surface charges that appear at and near the cylinder tips. As a result, the electric field close to the cylinder surface at the center plane of the coil increases by nearly $36 \%$. 
Another remarkable observation (this effect is common in MRI RF coils) follows from Fig. 5.3d where the conducting cylinder has been shifted from the coil axis to the right by $0.2 \mathrm{~m}$. While the electric field outside the conducting cylinder clearly changes, the field within the cylinder remains nearly the same, as observed in Fig. 5.3c. This may be explained as a result of the electric field being induced by the magnetic field, similar to eddy currents. Since the magnetic field is relatively homogeneous in the transverse plane of the coil, the induced electric fields in a load should not strongly depend on the transverse position of the load within the coil.

These rudimentary simulations allow us to establish two basic facts relevant for the analysis of realistic electric field distributions in a human body within the coil. First, we expect that the average transcutaneous electric field will be slightly higher than predicted by the air-filled coil model in dorsal, abdominal, and lumbar body regions. Second, we expect that the field within the body will not change significantly when the body is moved within the coil in the transverse plane; this circumstance seems to be useful from a practical point of view.

\subsubsection{Contribution of Unpaired Electric Charges}

Generally, the total electric field within the coil is expressed in terms of two auxiliary potentials. Instead of Eq. (5.1), one has

$$
\boldsymbol{E}=-\partial \boldsymbol{A} / \partial t-\nabla \varphi
$$

where $\varphi$ is the scalar electric potential and $\boldsymbol{A}$ is the magnetic vector potential. In the quasistatic approximation to Maxwell's equations, the time derivative in the Lorentz gauge $\frac{1}{c^{2}} \partial \varphi / \partial t+\nabla \cdot \boldsymbol{A}=0$ is neglected (which gives us the Coulomb gauge, $\nabla \cdot \boldsymbol{A}=0$ ), while it is still kept in Eq. (5.6). As a result, the $-\nabla \varphi$ term in Eq. (5.6) becomes a conservative electric field contribution due to charge density alone, while the $-\partial \boldsymbol{A} / \partial t$ term is a true solenoidal electric field contribution due to current density alone.

In accordance with the (quasi)electrostatic theory [90], the conservative electric field is blocked by charges induced on a surface of a conducting object and does not penetrate into the object. Therefore, its contribution is ignored in the present study, similar to the theoretical models of transcranial magnetic stimulation or TMS. Note that this charge contribution may be quite large in the present problem, close to the bridging capacitors.

We have also performed full-wave ANSYS ED simulations of this coil and found that the capacitor voltage drop E-field does not significantly affect the E-field within the patient. The externally applied conservative E-field is expelled from the patient by the high conductivity of tissues. Only the E-field induced from the B-field is important. 


\subsubsection{Power Amplifier/Driver}

In order to create the rotating magnetic and electric fields, as seen in Figs. 5.2a, b, two resonant modes are excited in the coil resonator. These modes display the same current distribution as shown in Fig. 5.3a, but rotated by 90 degrees about the coil axis with respect to each other as well as having an additional temporal phase shift of 90 degrees.

To accomplish this, a custom designed class-D, high-efficiency, single-frequency power amplifier (PA), whose circuit schematic is presented in Fig. 5.4a, was constructed and prototyped, as shown in Fig. 5.4b, c. The upper block in Fig. 5.4a is a class-S modulator, which is followed by two class-D output stages in quadrature, exciting the two resonant modes. The PA has two outputs, one for each resonant mode, and generates a harmonic power RF signal at a fixed carrier frequency at each output. At present, this frequency is typically around $100 \mathrm{kHz}$. At the same time, the same PA may be tuned to operate at any carrier frequency from $30 \mathrm{kHz}$ to $300 \mathrm{kHz}$ in the LF band. The PA operation, including variable power levels, an optional variable modulation or tonic frequency, and a semiautomatic patient-specific RF frequency tuning procedure, which is automated via a microcomputer board, can be seen in Figs. 5.4c and 5.5d.

The PA output stage is powered by a $3 \mathrm{~kW}$ Sorensen DCS 150-20 Variable Regulated DC (direct current) power supply seen at the bottom of Fig. 5.4c. When connected to a standard three-phase 208 VAC outlet, the max RF output power is about $2.9 \mathrm{~kW}$, based on $3 \mathrm{~kW}$ DC power. Alternatively, when connected into a single-phase $240 \mathrm{VAC}$ outlet, the max RF power reduces to about $2.3 \mathrm{~kW}$ based on $2.4 \mathrm{~kW}$ DC power.

Arbitrary modulation (pulse or $\mathrm{CW}$ ) of the carrier signal with a maximum modulation frequency component of $1 \mathrm{kHz}$ is available via the modulator. The modulation bandwidth is limited mainly by the coil envelope time constant of about $1 \mathrm{~ms}$. Typical modulation is sinusoidal in the $0.5-100 \mathrm{~Hz}$ range, generated by the PA firmware.

The PA also monitors its output power and load impedance. It uses this information to automatically adjust the carrier frequency in a narrow band such that the output power remains on target. The amplifier cost, including the DC power supply, is under $\$ 10,000$. The prototype $100 \mathrm{kHz} \mathrm{PA}$ was assembled in a rackmount case shown in Figs. 5.4b, c.

The reason for designing a custom, fixed-frequency PA is the lack of an affordable and appropriate commercial model. Industrial low-frequency RF power supplies, e.g., Comdel's CLB3000, are costly and require a matched $50 \Omega$ load. Because our load impedance varies widely with frequency, keeping the load matched is a challenge. It would require load impedance monitoring and fine frequency control (potentially difficult with a commercial unit), and/or a software-controlled matching network (costly). Additionally, generating two outputs in quadrature would require either a $90^{\circ}$ hybrid (another costly component), or phase-locking two commercial PAs at a $90^{\circ}$ phase difference, which can be difficult. Finally, the majority 

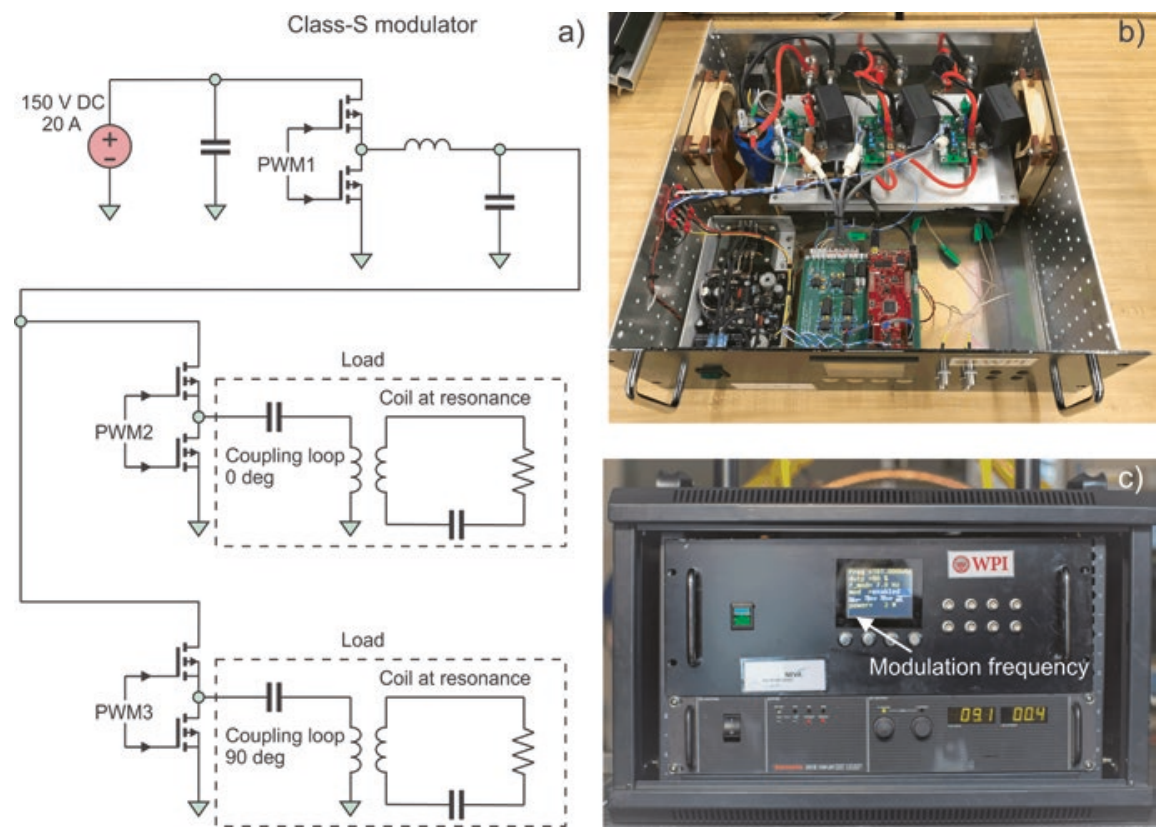

Fig. 5.4 (a) High-level circuit schematic of the two-channel power amplifier. (b) Rackmount aircooled assembly of the electronic hardware. (c) Amplifier display controlling output power and modulation frequency (if used)

of commercial PAs require water cooling, whereas our PA relies on air cooling. One disadvantage of our custom design is its unknown reliability, a factor that will be proven over time.

\subsubsection{Coupling and Matching the Power Amplifier to the Resonating Coil}

The amplifier is coupled to the resonating coil inductively via two proximate loops. One such loop is shown in Fig. 5.5c. Apart from certain technical advantages of the inductive coupling, this methodology assures that there is no direct current path from the AC power outlet to the coil. This design enhances overall device safety at any power level, including high-power operation.

The matching network for a single coil port is shown in Fig. 5.5a. Two ports with identical matching networks are located $90^{\circ}$ apart around the coil structure, as shown in Fig. 5.5b. The port matching network consists of a series capacitance $C_{1}$, series inductance $L_{1}$, and the fixed inductance $L_{2}$ of the inductive loop seen in Fig. 5.5c. 
a)
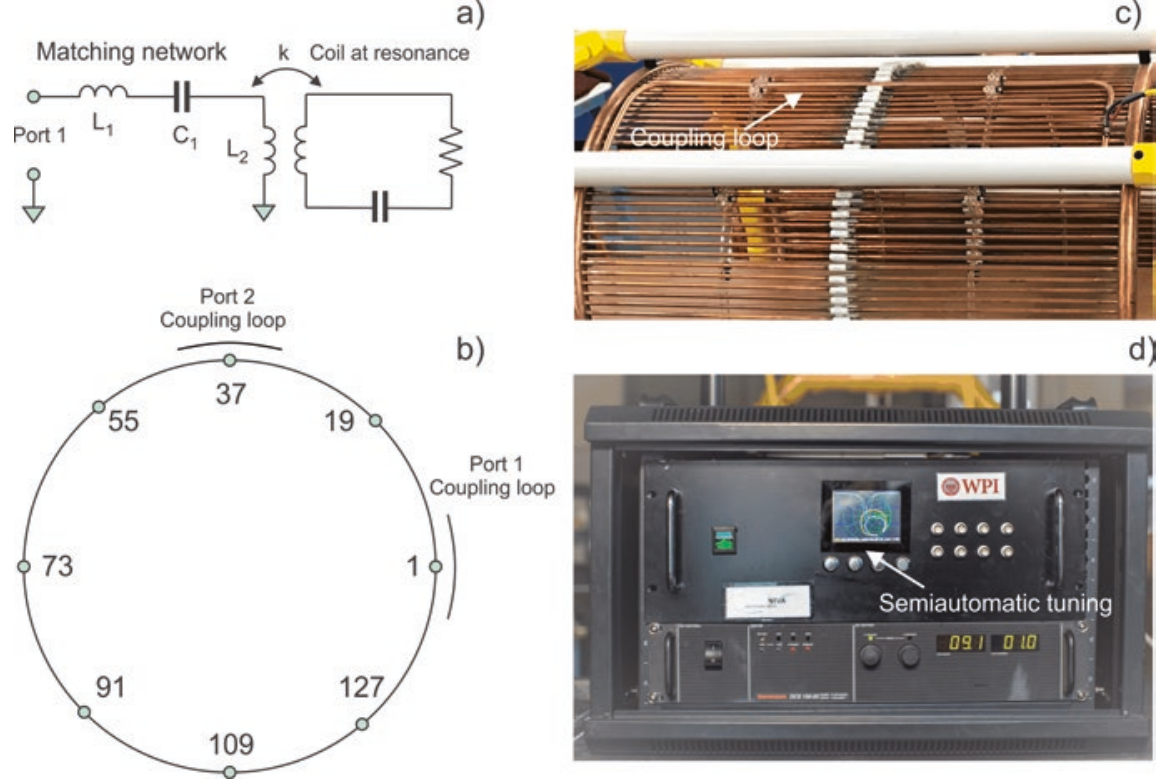

Fig. 5.5 (a) Matching and tuning network of the power amplifier. (b) Assembly of two couplingloop feed around the coil circumference with 144 rungs. (c) Noncontact inductive coupling of the power amplifier to the coil resonator at one port. (d) Smith chart/reflection coefficient display of the power amplifier controller used for semiautomatic tuning at any desired time instant

The matching network is tuned such that the load looks mostly resistive over a small frequency band around the coil's resonance. For example, the load reactance stays quite low from $99.85 \mathrm{kHz}$ to $100.15 \mathrm{kHz}$, while the resistance varies from $1.3 \Omega$ to $6 \Omega$. Because the coil resonance shifts as the coil heats up, the operating frequency must be actively adjusted to compensate for this change, or the output power will vary.

We used two Cornell Dubilier Electronics 940C20S47K-F per rung $(C=0.094 \mu \mathrm{F}$ per rung). These are $0.047 \mu \mathrm{F}, 2 \mathrm{kV}$ DC, $500 \mathrm{~V}$ AC-rated polypropylene film capacitors. They have a typical ESR of $12 \mathrm{~m} \Omega$ at $100 \mathrm{kHz}(Q=2800)$, and a max RMS current rating of $5.2 \mathrm{~A}$ at $70{ }^{\circ} \mathrm{C}$. We exceed this current rating by about $50 \%$ at full power. However, we have measured capacitor temperatures using an IR camera. They are below $70{ }^{\circ} \mathrm{C}$, well within the operating range.

Another important safety feature of the matching network is its benign power envelope step response. The matching network avoids large spikes in PA output current while energy is building up in the resonating coil.

Finally, the matching network presents a sufficiently inductive impedance to higher harmonics of the PA output voltage. This protects the output stage, and ensures that voltage transitions occur when the output current is low, thereby improving efficiency. The efficiency of the PA with the expected load is estimated to be greater than $90 \%$ over a wide output power range. 


\subsubsection{Tuning Procedure}

The primary adjustable components are the series capacitance $C_{1}$ in Fig. 5.5a and the coil rung capacitors at the numbered locations in Fig. 5.5b. First, the coil needs to be manually tuned by installing smaller capacitors in parallel with the primary coil capacitors at strategic locations. Coil adjustments include mode decoupling, tuning of each mode to the same frequency, and impedance matching for each mode (at the coupling loop). Since capacitance is normally only added, the coil only tunes down in frequency.

The semiautomatic tuning procedure implies adjusting PA frequency in a very narrow frequency range. It ensures that the reflection coefficient of both modes stays below $-25 \mathrm{~dB}$ when matched to the maximum-power coil impedance of $Z_{0}=2.5 \Omega$ and that both resonances are within a $20 \mathrm{~Hz}$ band. The tuning procedure is controlled and guided by the Smith chart/reflection coefficient display of the PA controller seen in Fig. 5.5d. It includes a number of well-defined steps, and is applied to the coil at its designated operating location in an effort to account for the presence of large nearby metal objects. The tuning procedure is simple to perform.

\subsubsection{Coil Assembly, Device Setup, and Operation}

A resonator coil prototype made of thin-walled, light copper tubing was constructed; it is shown in Figs. 5.6a, b and 5.7. Tubing thickness was kept at $3 / 4 \mathrm{~mm}$ or greater to avoid excessive eddy current losses in the copper. The capacitor size in Fig. 5.6a is relatively large since those components must operate at significant currents levels, up to $18 \mathrm{~A}$ RMS per rung for a maximum power of $3 \mathrm{~kW}$, and at large voltages, up to $300 \mathrm{~V}$ RMS across the capacitor. The total coil weight without the frame is approximately $120 \mathrm{lbs}$. (54 kg).

This durable coil prototype was then framed, augmented with a horizontal bed, and placed horizontally to enable a subject to rest in the coil, as shown in Fig. 5.6a, which simultaneously shows the complete device setup. The entire coil frame is portable. The distance between the PA, which is connected to the inductive coupling loops of the coil via two isolated cables, can vary from 1 to $3 \mathrm{~m}$, although larger distances may be possible. As mentioned above, there is no direct ohmic current path from the AC power outlet to the coil, which is an important safety feature.

An operator sets the power level, the modulation frequency, and performs RF tuning at the beginning of the resonator operation and for a particular coil load. At the maximum power level, the ring conductors of the coil heat up to approximately $70-75^{\circ} \mathrm{C}$ at continuous operation, as illustrated in Fig. 5.8. Continuous coil operation at the maximum input power of $3 \mathrm{~kW}$ was tested multiple times with an uninterrupted operation time of up to $2 \mathrm{~h}$ and with a cumulative operating time in excess of $100 \mathrm{~h}$. 


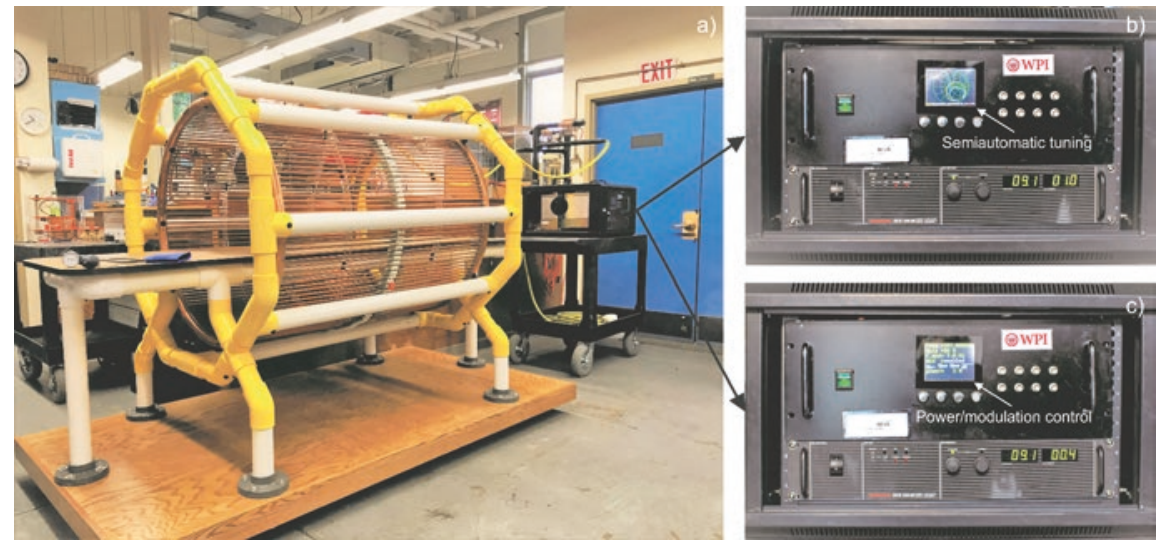

Fig. 5.6 (a) Complete framed resonator coil unit with the PA. (b) Smith chart/reflection coefficient display of the power amplifier controller to be used for semiautomatic tuning for an individual subject/patient. (c) Amplifier display controlling output power and modulation frequency for harmonic modulation

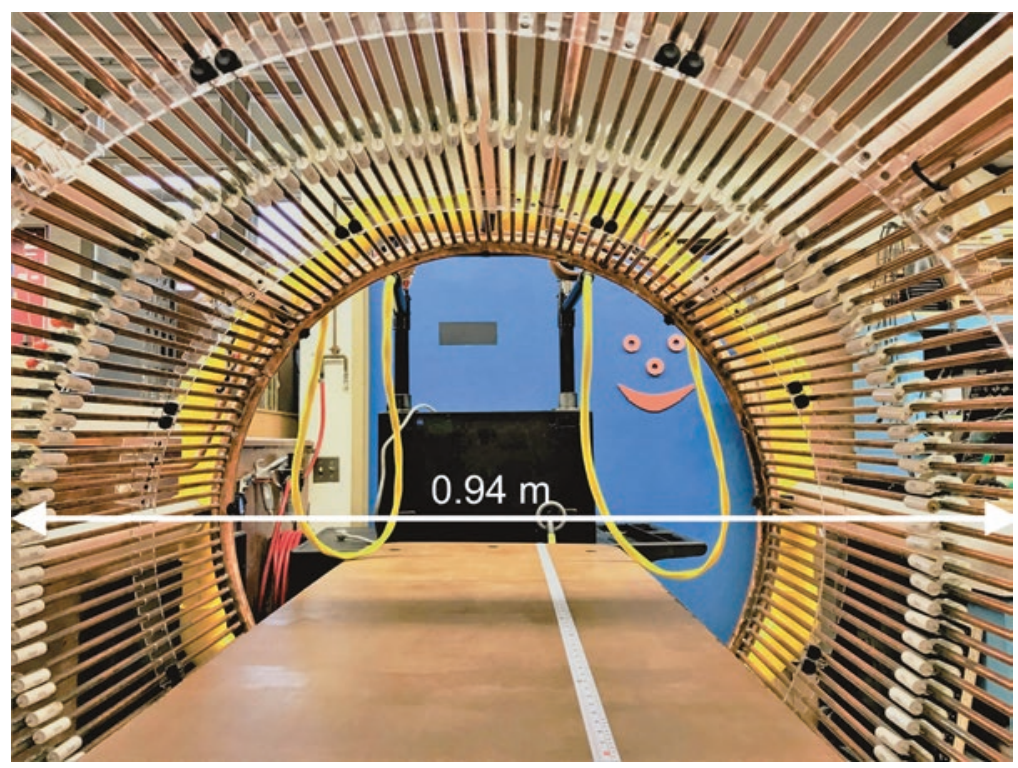

Fig. 5.7 Active area of the subthreshold resonator device 


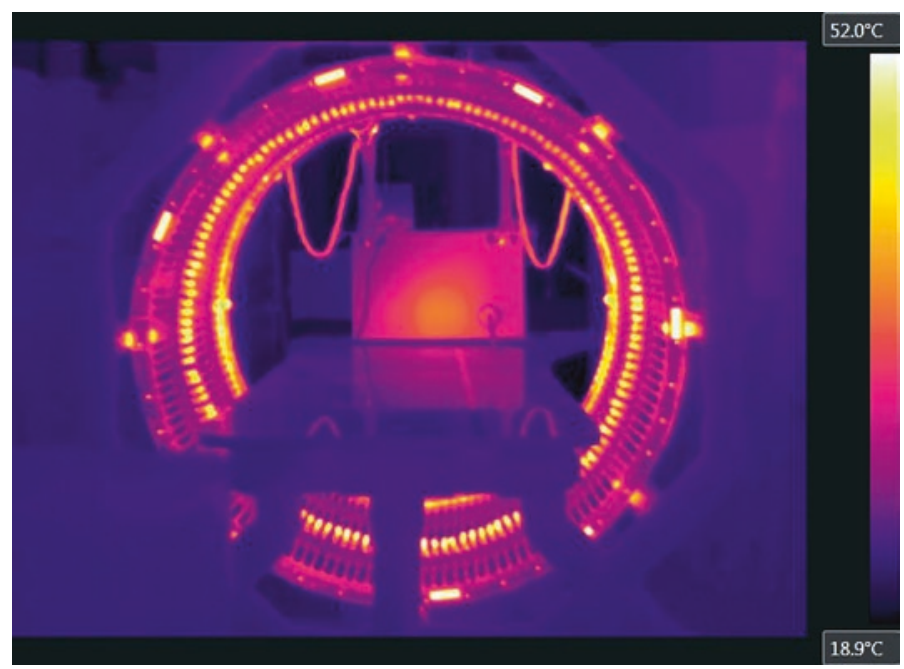

Fig. 5.8 Infrared map of the coil and PA(rear) temperature distribution after $30 \mathrm{~min}$ of operation at maximum power obtained with FLIR A325sc IR camera

\subsubsection{Quality Factor of the Resonator and the Magnetic Field Strength}

The achievable field strength in the coil is determined by three factors: the strength of the PA, the quality factor $Q$ or the "gain" of the resonator, and the coil volume. When the quality factor is high, large field values within the coil can be achieved at a modest input power.

When measured across one of its rung capacitors, the birdcage coil behaves like a parallel resonator in a narrow frequency range around the resonant mode. Using a setup with a signal generator and oscilloscope, the resonator's quality factor has been estimated in the form:

$$
Q=\frac{f_{0}}{\left(f_{\mathrm{U}}-f_{\mathrm{L}}\right)\left(1-\frac{V_{1}}{V_{0}}\right)}
$$

where $f_{0}$ is the resonance frequency and voltage $V_{0}$ is the open-circuited generator voltage. Derivation of Eq. (5.7) is given in Appendix A. Voltage $V_{1}$ is measured at resonance (where it is maximized). $f_{\mathrm{L}}$ and $f_{\mathrm{U}}$ are the lower and upper frequencies, respectively, where voltage $V_{1}$ drops by $3 \mathrm{~dB}$ from its peak at resonance. This method is accurate in the high $Q$ limit. The experimental data for $100 \mathrm{kHz}$ and $145 \mathrm{kHz}$ are given in Table 5.1. Table 5.1 reports a $Q$-factor value of about 300 and 
Table 5.1 Measured $Q$-factors for the coil resonator at $100 \mathrm{kHz}$ and $145 \mathrm{kHz}$, respectively

\begin{tabular}{l|l|l|l|l}
\hline Coil & $f_{0}, \mathrm{kHz}$ & $f_{\mathrm{L}}, \mathrm{kHz}$ & $f_{\mathrm{U}}, \mathrm{kHz}$ & $Q$ \\
\hline Unloaded & 145.30 & 144.567 & 145.875 & 295.8 \\
\hline Loaded & 145.28 & 144.566 & 145.879 & 292.2 \\
\hline Unloaded & 101.42 & 101.008 & 101.827 & 277.3 \\
\hline Loaded & 101.43 & 101.009 & 101.835 & 275.0
\end{tabular}

The load is a $200 \mathrm{lb}$. subject

Table 5.2 Characteristics of existing low-frequency RF coils given for comparison with the present resonator prototype

\begin{tabular}{l|l|l|l}
\hline Ref.\# & Type of the coil & $\begin{array}{l}\text { Frequency, } \\
\mathrm{kHz}\end{array}$ & $Q$ (unloaded) \\
\hline$[83]$ & $\begin{array}{l}\text { Wound birdcage coil (84 mm long and has a diameter of } \\
73 \mathrm{~mm})\end{array}$ & 386 & 180 \\
\hline$[84]$ & $\begin{array}{l}\text { Wound birdcage coils and a solenoid. The diameter and } \\
\text { the length of the coils are 70 mm }\end{array}$ & $238 / 425$ & $100-280$ \\
\hline$[85]$ & $\begin{array}{l}27 \text { tTurn saddle coil made of Litz wire with } 8 \mathrm{~cm} \\
\text { diameter }\end{array}$ & 373 & 105 \\
\hline$[86]$ & 4-Coil Whiting-Lee configuration, 33 cm long & 83.6 & 100 \\
\hline$[87]$ & $\begin{array}{l}\text { Solenoidal coils; 6-46 cm in length and 4-52 cm in } \\
\text { diameter }\end{array}$ & $210 / 275$ & $\begin{array}{l}60-30, \\
\text { reduced } Q\end{array}$ \\
\hline$[88]$ & $\begin{array}{l}\text { Cylindrical saddle-shaped loops (5 saddle pairs of } 10 \\
\text { turns each), coil diameter is 26 mm }\end{array}$ & 87 & NA \\
\hline
\end{tabular}

a minimum difference between loaded (with a human body) and unloaded coil, which is to be expected at this low frequency. These values agree with the theoretical/ simulation predictions to within $10 \%$. With decreasing frequency, the $Q$-factor will decrease approximately proportional to the square root of the resonant frequency.

The established quality factor values are superior to the values reported in the literature for known low-frequency resonator coils (used for low-field MRI) in Table 5.2. Note that all listed competitors have a much smaller coil size/volume and typically a lower quality factor.

It is important to point out again that the quality factor in Table 5.1 is weakly affected by body loading, in contrast to conventional high-frequency MRI RF coils. This observation, also mentioned in Ref. [84] and other sources, is a limitation of the present electromagnetic stimulator. The RF power losses are mostly in the coil itself, and not in the human body.

B-field measurements have been performed via a calibrated single-axis coil probe located at the coil axis. The B-field magnitude was $1.01 \mathrm{mT}$ at the coil center and at full power ( $3 \mathrm{~kW} \mathrm{DC}$ ) at $100 \mathrm{kHz}$. The measured and theoretical results differ by no more than $10 \%$. At the full input power level of $3 \mathrm{~kW}$, the amplitude of the resonant ring current $I_{0}$ at $100 \mathrm{kHz}$ in two coil rings reaches $603 \mathrm{~A}$, while the amplitude of the rung current reaches $26 \mathrm{~A}$. 


\subsection{Device Safety Estimates}

\subsubsection{Peripheral Nervous System (PNS) Stimulation Threshold}

The present low-frequency subthreshold electrostimulation device must not exceed the PNS simulation threshold to operate safely and without unpleasant sensation. Guidelines from the International Commission on Non-Ionizing Radiation Protection (Table 5.2 of [91]) require the occupational exposure to an electric field to be limited to a value of approximately $27 \mathrm{~V} / \mathrm{m} \mathrm{RMS}$ at $100 \mathrm{kHz}$ and by a value of $39 \mathrm{~V} / \mathrm{m}$ RMS at $145 \mathrm{kHz}$ (the so-called basic restrictions [91]). These restrictions are mainly due to limits on peripheral nerve stimulation [91] and should therefore be respected. Other relevant results on the PNS stimulation thresholds at lower frequencies are presented in Refs. [92-94].

\subsubsection{Specific Absorption Rate (SAR)}

Safety estimates also rely upon the levels of the specific absorption rate (SAR) within the body. The SAR is the energy absorption rate that causes body temperature to rise due to an imposed electromagnetic field. The maximum value of $S A R_{1 g}$ in the body must be below $10 \mathrm{~W} / \mathrm{kg}$ required by the FDA-accepted safety standard $[95,96]$. The global-body $S A R$ must be below the $2 \mathrm{~W} / \mathrm{kg}$ limit $[95,96]$.

\subsubsection{Method of Analysis}

SAR and electric field measurements cannot be performed easily for human subjects in vivo. SAR and device performance estimates are typically derived and accepted today from computational electromagnetics (CEM) simulations performed with detailed virtual humans [97]. In this study, we use the multi-tissue CEM phantom VHP-Female v. 5.0 (female/60 year/162 cm/88 kg, obese) [97-103] derived from the cryosection dataset archived within the Visible Human Project ${ }^{\circledR}$ of the US National Library of Medicine [104]. The phantom includes about 250 individual tissues and is augmented with material property values from the IT'IS database [105]. The average-body conductivity is assigned as $0.25 \mathrm{~S} / \mathrm{m}$, which reflects a mixture of muscle and fat.

The primary CEM software used in this study is the accurate commercial FEM solver ANSYS® Electromagnetic Suite 18.2.0 with rigorous adaptive mesh refinement. In addition, and for verification/validation purposes, we employ an in-house boundary element fast multipole method (BEM-FMM) described in Ref. [89]. In the latter case, a higher near-surface resolution can be achieved and the original surface phantom model can be refined and smoothed from approximately $0.5 \mathrm{M}$ 
triangles to $3.5 \mathrm{M}$ triangles. In this particular study, the human model is placed in the coil at the shoulder landmark, as shown in Fig. 5.9, so that the top of the shoulder coincides with the ring plane. Other configurations have also been considered.

Results obtained with both software packages differ by no more than $2 \%$ in the unloaded coil (field at the coil center) and by no more than $25-50 \%$ in the coil loaded with the multi-tissue human body. The latter deviation may be explained by somewhat different surface meshes.

Below we report simulations at two power levels: $1.5 \mathrm{~kW}$ input power and $3 \mathrm{~kW}$ input power. The first power level is the half power level of the amplifier driver; the second power level corresponds to full power. At full power level, the amplitude of the resonant ring current $I_{0}$ in Eqs. (5.4 and 5.5) reaches $603 \mathrm{~A}$, while the amplitude of the rung current reaches $26 \mathrm{~A}$.

\subsubsection{Electric Field Levels}

Figure 5.10 shows the simulated RMS levels of the electric field in the body at $100 \mathrm{kHz}$ and at the input power level of $1.5 \mathrm{~kW}$ obtained via the BEM-FMM simulations. We observe that, at half power level of the amplifier driver, the fields everywhere in the body do not generally exceed $30 \mathrm{~V} / \mathrm{m}$ RMS and are thus within the

Fig. 5.9 Multi-tissue CEM phantom VHPFemale v. 5.0 within the resonant coil (ANSYS 18.2.0)

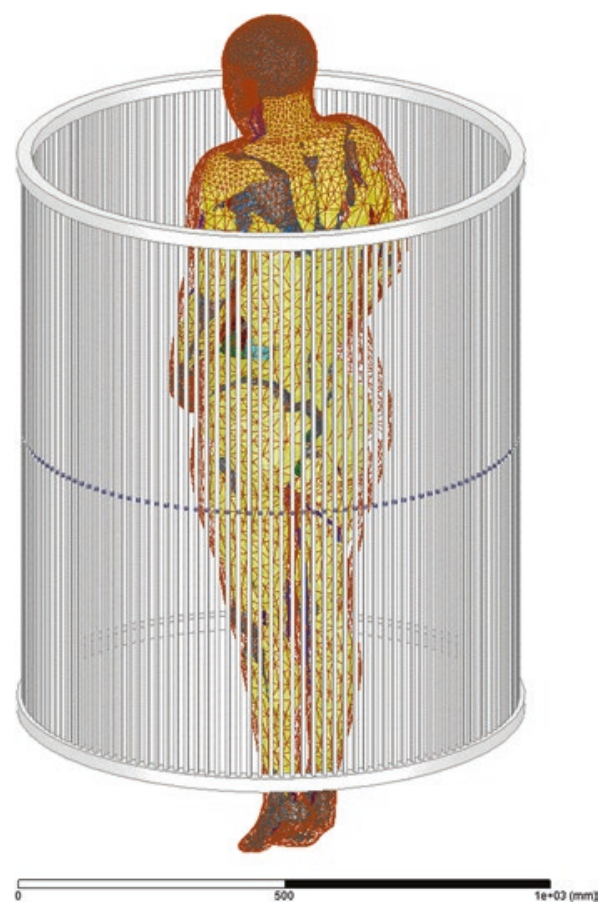




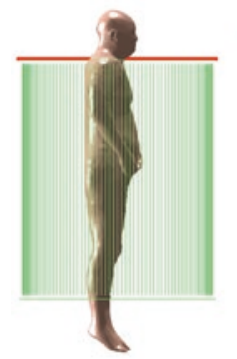

a)
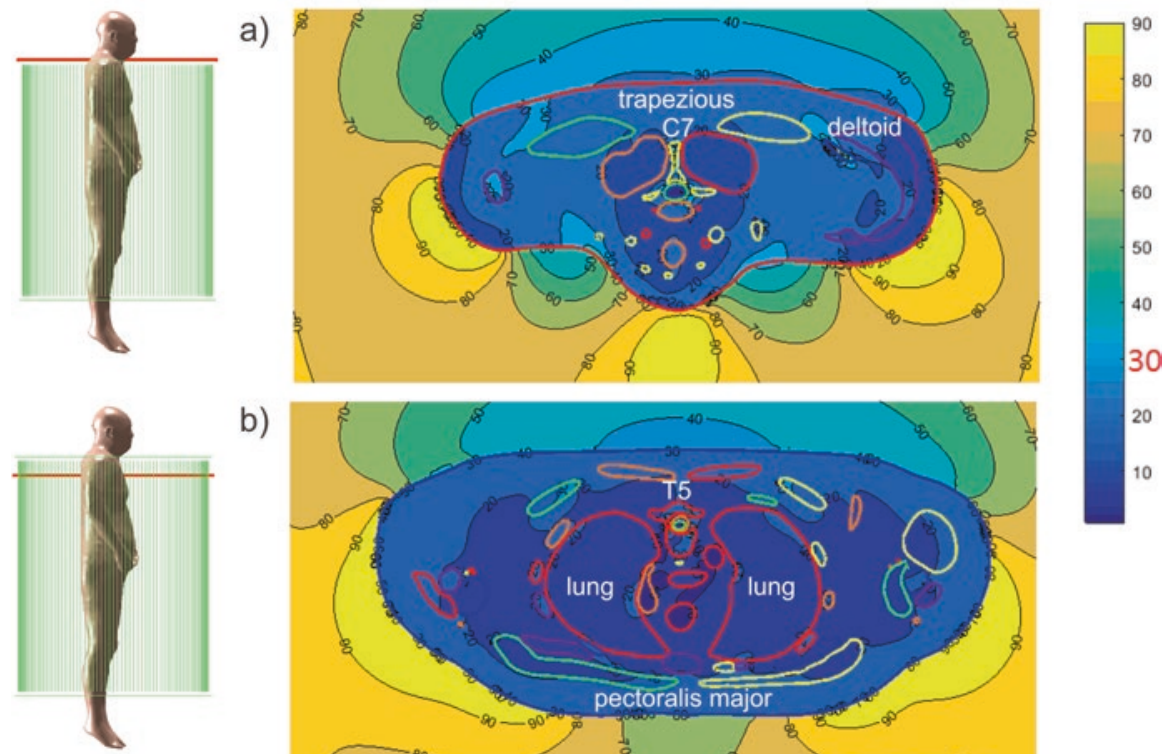

b)
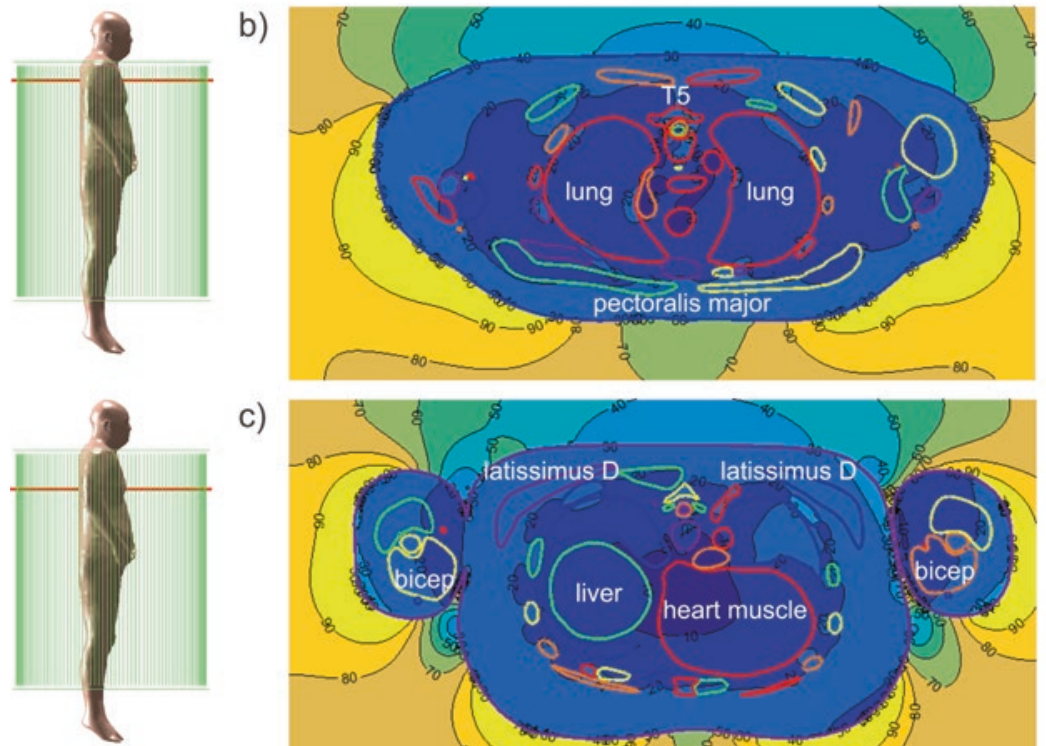

c)
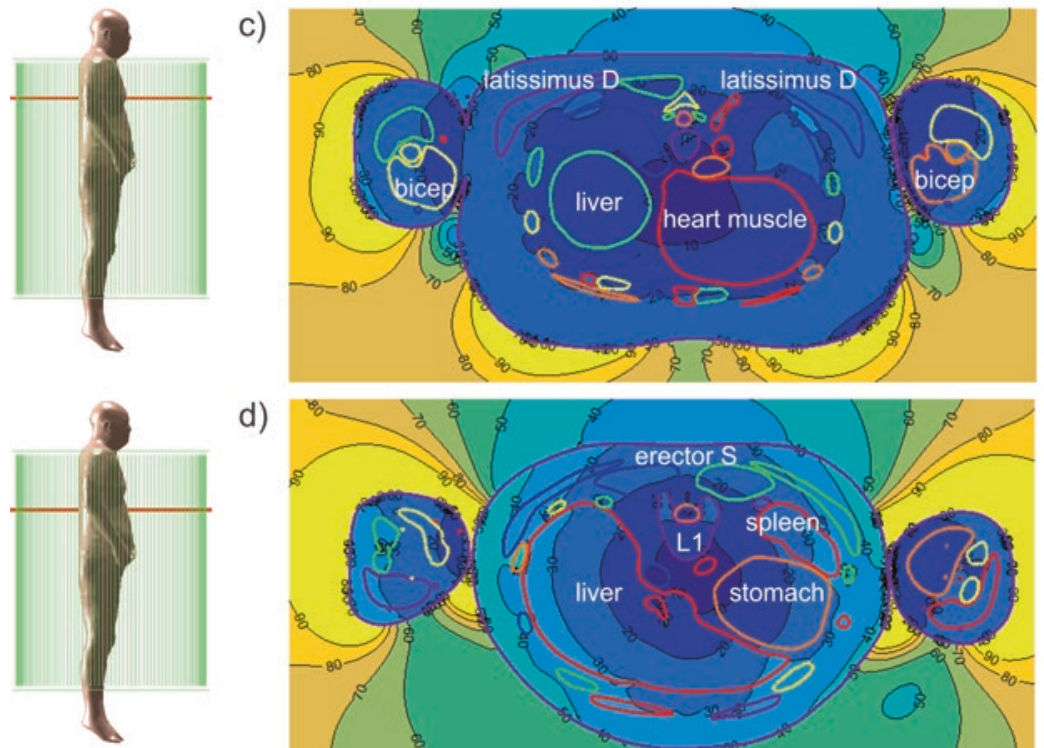

d)

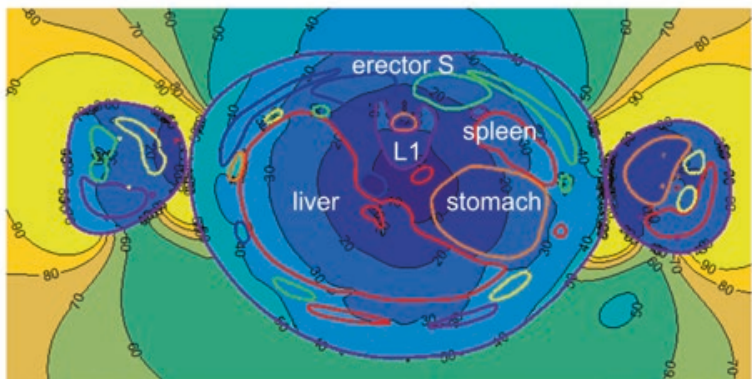

Fig. 5.10 Complex RMS magnitude of the electric field $(\mathrm{V} / \mathrm{m})$ at $1500 \mathrm{~W}$ input power 
5 Design and Analysis of a Whole-Body Noncontact Electromagnetic Subthreshold...

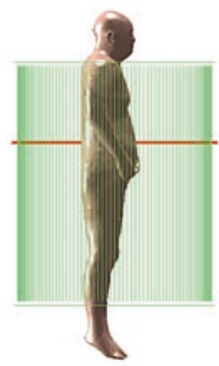

e)
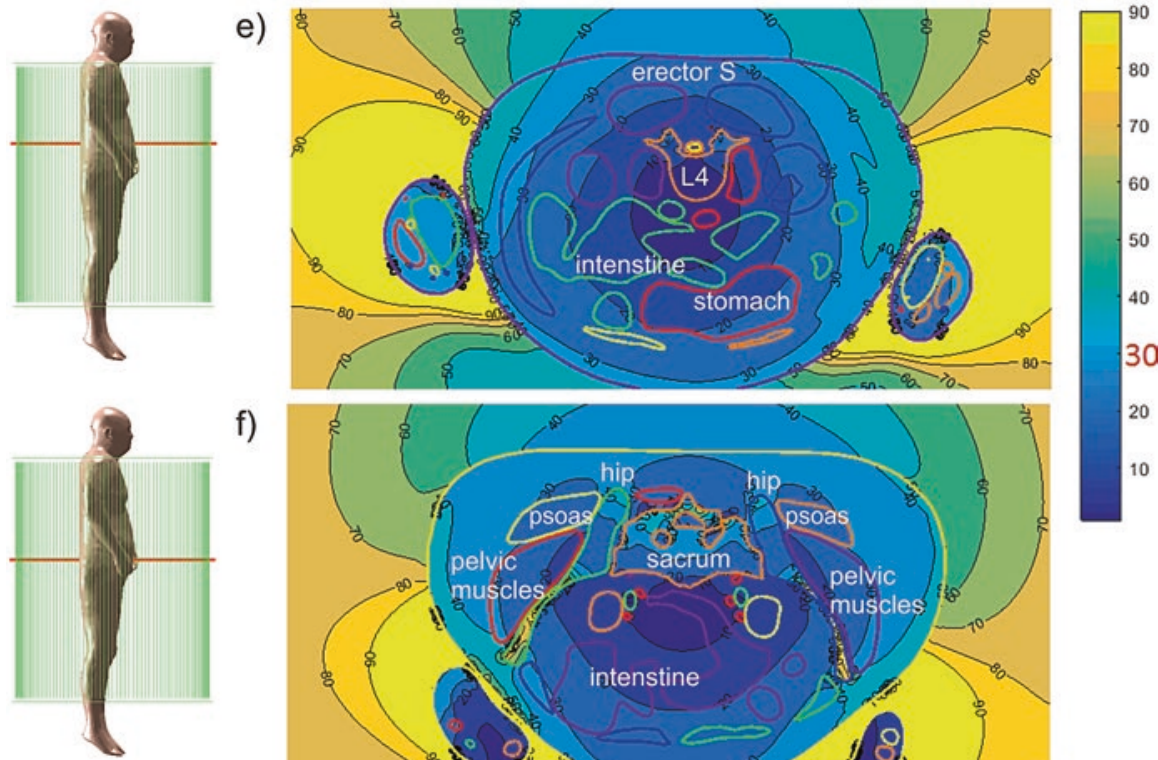

f)
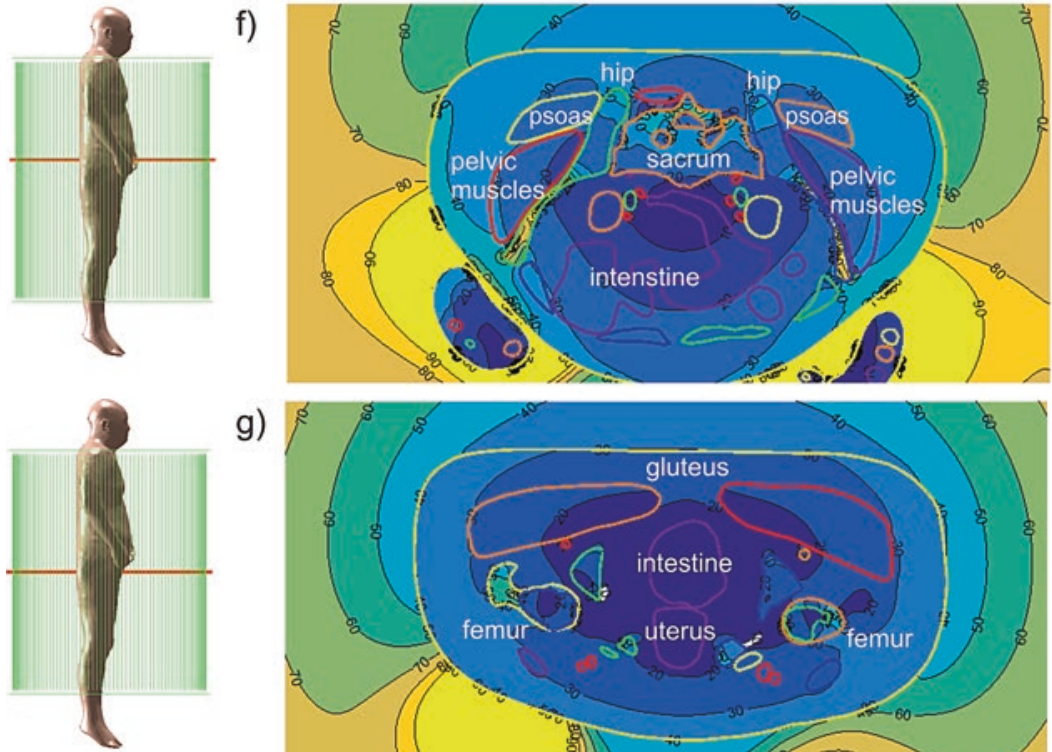

g)
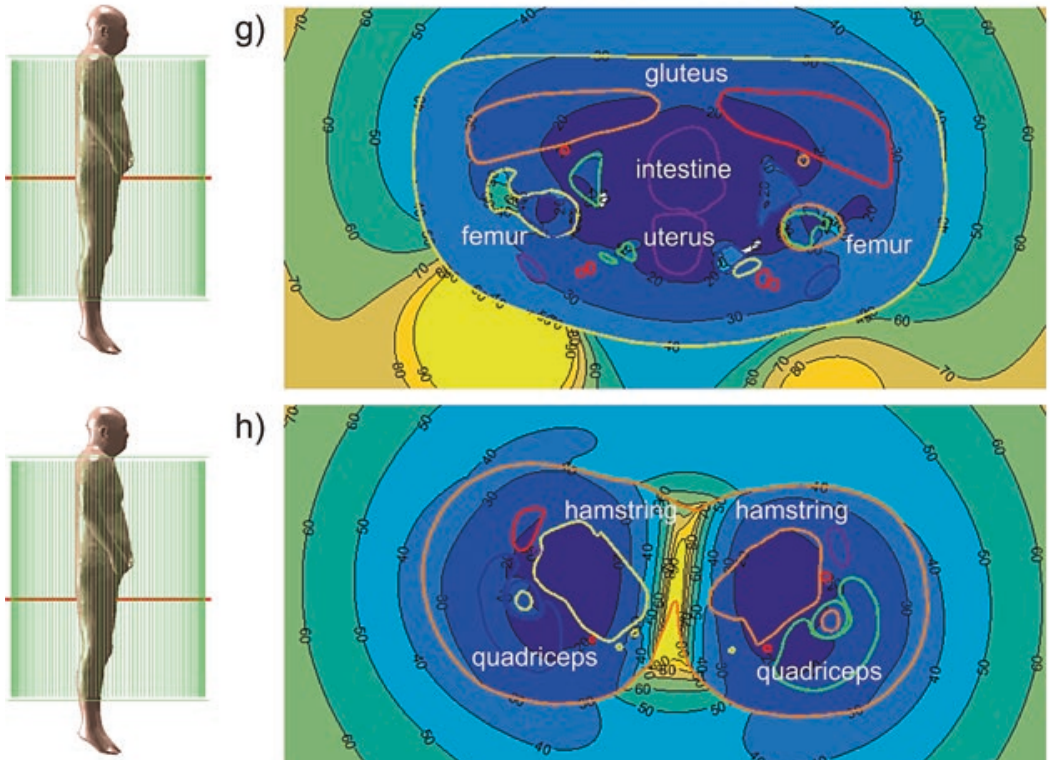

h)

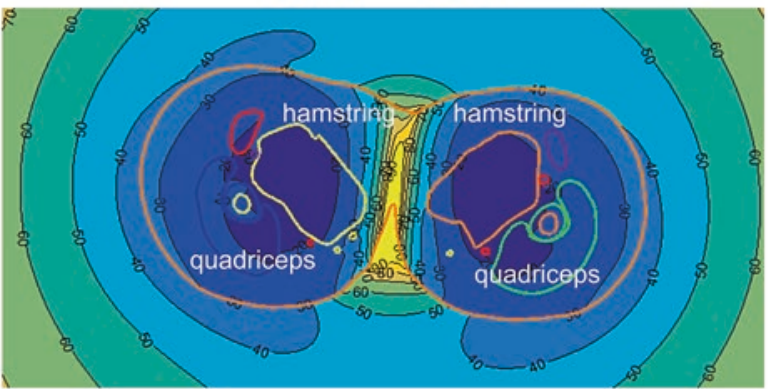

Fig. 5.10 (continued) 
Table 5.3 Computed electric field levels (V/m RMS) in every individual tissue at $1.5 \mathrm{~kW}$ input power (ANSYS® Electromagnetic Suite 18.2.0)

\begin{tabular}{|c|c|c|c|c|c|}
\hline Mesh & Tissue & $\begin{array}{l}\text { Avg. E field } \\
(\text { V/m RMS) }\end{array}$ & Mesh & Tissue & $\begin{array}{l}\text { Avg. E field } \\
\text { (V/m RMS) }\end{array}$ \\
\hline 1 & $\begin{array}{l}\text { Air Internal Maxillary } \\
\text { Sinus Left }\end{array}$ & 7.7 & 39 & $\begin{array}{l}\text { Cuneiform Medial } \\
\text { right }\end{array}$ & 0.6 \\
\hline 2 & $\begin{array}{l}\text { Air Internal Maxillary } \\
\text { Sinus Right }\end{array}$ & 6.9 & 40 & $\operatorname{discC} 02 \mathrm{C} 03$ & 10.3 \\
\hline 3 & Arteries & 10.5 & 41 & discC03C04 & 11.6 \\
\hline 4 & Bladder & 28.0 & 42 & discC04C05 & 14.3 \\
\hline 5 & $\mathrm{C} 01$ & 14.5 & 43 & discC05C06 & 16.9 \\
\hline 6 & $\mathrm{C} 02$ & 13.6 & 44 & $\operatorname{discC} 06 \mathrm{C} 07$ & 19.0 \\
\hline 7 & $\mathrm{C} 03$ & 14.8 & 45 & discC07T01 & 20.6 \\
\hline 8 & $\mathrm{C} 04$ & 18.5 & 46 & discL01L02 & 13.9 \\
\hline 9 & $\mathrm{C} 05$ & 21.7 & 47 & discL02L03 & 11.5 \\
\hline 10 & C06 & 26.1 & 48 & discL03L04 & 8.4 \\
\hline 11 & $\mathrm{C} 07$ & 29.6 & 49 & discL04L05 & 4.7 \\
\hline 12 & Calcaneous left & 0.6 & 50 & discL05L06 & 7.1 \\
\hline 13 & Calcaneous right & 1.1 & 51 & discL06S00 & 13.8 \\
\hline 14 & Cartilage1 Left & 18.5 & 52 & discT01T02 & 20.2 \\
\hline 15 & Cartilage1 Right & 19.9 & 53 & discT02T03 & 17.6 \\
\hline 16 & Cartilage2 Left & 19.7 & 54 & discT03T04 & 17.9 \\
\hline 17 & Cartilage2 Right & 20.3 & 55 & discT04T05 & 17.4 \\
\hline 18 & Cartilage3 Left & 21.2 & 56 & discT05T06 & 15.8 \\
\hline 19 & Cartilage3 Right & 20.9 & 57 & discT06T07 & 15.2 \\
\hline 20 & Cartilage4 Left & 22.5 & 58 & discT07T08 & 14.4 \\
\hline 21 & Cartilage4 Right & 21.8 & 59 & discT08T09 & 13.6 \\
\hline 22 & Cartilage5 Left & 24.3 & 60 & discT09T10 & 13.2 \\
\hline 23 & Cartilage5 Right & 22.6 & 61 & discT10T11 & 12.5 \\
\hline 24 & Cartilage6 Left & 36.3 & 62 & discT11T12 & 13.2 \\
\hline 25 & Cartilage6 Right & 35.9 & 63 & discT12L01 & 13.4 \\
\hline 26 & Cerebellum & 1.4 & 64 & Eye Left & 5.0 \\
\hline 27 & Clavicle left & 55.6 & 65 & Eye Right & 5.3 \\
\hline 28 & Clavicle right & 34.9 & 66 & Feet1Phalange left & 0.5 \\
\hline 29 & Coccyx & 42.6 & 67 & Feet1Phalange right & 0.4 \\
\hline 30 & CSF OuterShell & 3.5 & 68 & Feet2Phalange left & 0.4 \\
\hline 31 & CSF Ventricles & 0.4 & 69 & Feet2Phalange right & 0.4 \\
\hline 32 & Cuboid Left & 0.9 & 70 & Feet3Phalange left & 0.3 \\
\hline 33 & Cuboid Right & 0.6 & 71 & Feet3Phalange right & 0.4 \\
\hline 34 & $\begin{array}{l}\text { Cuneiform Intermediate } \\
\text { left }\end{array}$ & 1.3 & 72 & Feet4Phalange left & 0.4 \\
\hline 35 & $\begin{array}{l}\text { Cuneiform Intermediate } \\
\text { right }\end{array}$ & 0.5 & 73 & Feet4Phalange right & 0.6 \\
\hline 36 & Cuneiform Lateral left & 1.1 & 74 & Feet5Phalange left & 0.4 \\
\hline 37 & Cuneiform Lateral right & 0.4 & 75 & Feet5Phalange right & 0.7 \\
\hline
\end{tabular}




\begin{tabular}{|c|c|c|c|c|c|}
\hline Mesh & Tissue & $\begin{array}{l}\text { Avg. E field } \\
\text { (V/m RMS) }\end{array}$ & Mesh & Tissue & $\begin{array}{l}\text { Avg. E field } \\
\text { (V/m RMS) }\end{array}$ \\
\hline 38 & Cuneiform Medial left & 1.3 & 76 & $\begin{array}{l}\text { Femur Bone Marrow } \\
\text { Left }\end{array}$ & 7.1 \\
\hline 77 & $\begin{array}{l}\text { Femur Bone Marrow } \\
\text { Right }\end{array}$ & 8.6 & 117 & Humerus right & 23.1 \\
\hline 78 & Femur left & 69.3 & 118 & Intestine & 20.6 \\
\hline 79 & Femur right & 83.7 & 119 & Jaw lower & 10.0 \\
\hline 80 & Fibula left & 5.9 & 120 & Kidney left & 29.3 \\
\hline 81 & Fibula right & 5.4 & 121 & Kidney right & 27.2 \\
\hline 82 & Gray Matter Spinal Cord & 1.5 & 122 & L01 & 27.9 \\
\hline 83 & Hands1 1Phalange left & 10.2 & 123 & L02 & 25.3 \\
\hline 84 & Hands1 1Phalange right & 9.5 & 124 & L03 & 22.1 \\
\hline 85 & Hands1 2Phalange left & 9.5 & 125 & L04 & 19.0 \\
\hline 86 & Hands1 2Phalange right & 12.1 & 126 & L05 & 14.4 \\
\hline 87 & Hands1 3Phalange left & 12.2 & 127 & L06 & 17.9 \\
\hline 88 & Hands1 3Phalange right & 13.4 & 128 & Liver & 29.8 \\
\hline 89 & Hands2 1Phalange left & 7.6 & 129 & Lungs & 19.4 \\
\hline 90 & Hands2 1Phalange right & 7.1 & 130 & Median Nerve left & 11.6 \\
\hline 91 & Hands2 2Phalange left & 8.1 & 131 & Median Nerve right & 13.0 \\
\hline 92 & Hands2 2Phalange right & 8.5 & 132 & Muscle Bicep left & 11.9 \\
\hline 93 & Hands2 3Phalange left & 7.1 & 133 & Muscle Bicep right & 12.9 \\
\hline 94 & Hands2 3Phalange right & 9.5 & 134 & Muscle Calf left & 5.0 \\
\hline 95 & Hands3 1Phalange left & 6.4 & 135 & Muscle Calf right & 5.2 \\
\hline 96 & Hands3 1Phalange right & 6.2 & 136 & Muscle Deltoid left & 18.7 \\
\hline 97 & Hands3 2Phalange left & 8.1 & 137 & Muscle Deltoid right & 19.3 \\
\hline 98 & Hands3 2Phalange right & 8.6 & 138 & $\begin{array}{l}\text { Muscle Erector spinae } \\
\text { left }\end{array}$ & 26.8 \\
\hline 99 & Hands3 3Phalange left & 9.3 & 139 & $\begin{array}{l}\text { Muscle Erector spinae } \\
\text { right }\end{array}$ & 26.9 \\
\hline 100 & Hands3 3Phalange right & 11.0 & 140 & $\begin{array}{l}\text { Muscle Forearm } \\
\text { Extensors left }\end{array}$ & 6.9 \\
\hline 101 & Hands4 1Phalange left & 7.2 & 141 & $\begin{array}{l}\text { Muscle Forearm } \\
\text { Extensors right }\end{array}$ & 8.6 \\
\hline 102 & Hands4 1Phalange right & 6.9 & 142 & $\begin{array}{l}\text { Muscle Forearm } \\
\text { Flexors left }\end{array}$ & 6.9 \\
\hline 103 & Hands4 2Phalange left & 10.4 & 143 & $\begin{array}{l}\text { Muscle Forearm } \\
\text { Flexors right }\end{array}$ & 7.2 \\
\hline 104 & Hands4 2Phalange right & 10.0 & 144 & Muscle Gluteus left & 27.9 \\
\hline 105 & Hands4 3Phalange left & 11.1 & 145 & Muscle Gluteus right & 27.2 \\
\hline 106 & Hands4 3Phalange right & 10.7 & 146 & Muscle Hamstring left & 18.9 \\
\hline 107 & Hands5 1Phalange left & 9.0 & 147 & $\begin{array}{l}\text { Muscle Hamstring } \\
\text { right }\end{array}$ & 19.1 \\
\hline 108 & Hands5 1Phalange right & 10.3 & 148 & $\begin{array}{l}\text { Muscle Latissimus } \\
\text { Dorsi left }\end{array}$ & 36.6 \\
\hline
\end{tabular}


Table 5.3 (continued)

\begin{tabular}{|c|c|c|c|c|c|}
\hline Mesh & Tissue & $\begin{array}{l}\text { Avg. E field } \\
\text { (V/m RMS) }\end{array}$ & Mesh & Tissue & $\begin{array}{l}\text { Avg. E field } \\
\text { (V/m RMS) }\end{array}$ \\
\hline 109 & Hands5 2Phalange left & 11.0 & 149 & $\begin{array}{l}\text { Muscle Latissimus } \\
\text { Dorsi right }\end{array}$ & 38.5 \\
\hline 110 & Hands5 2Phalange right & 12.6 & 150 & $\begin{array}{l}\text { Muscle Neck } \\
\text { Combined left }\end{array}$ & 13.6 \\
\hline 111 & Hands5 3Phalange left & 10.3 & 151 & $\begin{array}{l}\text { Muscle Neck } \\
\text { Combined right }\end{array}$ & 13.4 \\
\hline 112 & Hands5 3Phalange right & 12.1 & 152 & Muscle Obliques left & 39.5 \\
\hline 113 & Heart Muscle & 14.2 & 153 & Muscle Obliques right & 40.1 \\
\hline 114 & Hip left & 60.0 & 154 & $\begin{array}{l}\text { Muscle Pectoralis } \\
\text { major left }\end{array}$ & 21.7 \\
\hline 115 & Hip right & 61.4 & 155 & $\begin{array}{l}\text { Muscle Pectoralis } \\
\text { major right }\end{array}$ & 20.9 \\
\hline 116 & Humerus left & 20.7 & 156 & $\begin{array}{l}\text { Muscle Pectoralis } \\
\text { minor left }\end{array}$ & 19.2 \\
\hline 157 & $\begin{array}{l}\text { Muscle Pectoralis minor } \\
\text { right }\end{array}$ & 18.6 & 194 & Ribs left8 & 47.3 \\
\hline 158 & $\begin{array}{l}\text { Muscle Pelvic } \\
\text { Combined left }\end{array}$ & 25.7 & 195 & Ribs left 9 & 46.1 \\
\hline 159 & $\begin{array}{l}\text { Muscle Pelvic } \\
\text { Combined right }\end{array}$ & 25.0 & 196 & Ribs left10 & 48.5 \\
\hline 160 & Muscle Psoas left & 13.9 & 197 & Ribs left11 & 51.7 \\
\hline 161 & Muscle Psoas right & 13.9 & 198 & Ribs left12 & 39.0 \\
\hline 162 & Muscle Quadriceps left & 20.2 & 199 & Ribs right1 & 29.6 \\
\hline 163 & Muscle Quadriceps right & 19.9 & 200 & Ribs right 2 & 26.2 \\
\hline 164 & $\begin{array}{l}\text { Muscle Rectus } \\
\text { Abdominis left bottom }\end{array}$ & 32.3 & 201 & Ribs right 3 & 25.2 \\
\hline 165 & $\begin{array}{l}\text { Muscle Rectus } \\
\text { Abdominis left middle }\end{array}$ & 34.9 & 202 & Ribs right 4 & 26.1 \\
\hline 166 & $\begin{array}{l}\text { Muscle Rectus } \\
\text { Abdominis left top }\end{array}$ & 39.1 & 203 & Ribs right5 & 27.2 \\
\hline 167 & $\begin{array}{l}\text { Muscle Rectus } \\
\text { Abdominis right bottom }\end{array}$ & 32.5 & 204 & Ribs right6 & 29.9 \\
\hline 168 & $\begin{array}{l}\text { Muscle Rectus } \\
\text { Abdominis right middle }\end{array}$ & 35.4 & 205 & Ribs right7 & 35.6 \\
\hline 169 & $\begin{array}{l}\text { Muscle Rectus } \\
\text { Abdominis right top }\end{array}$ & 38.1 & 206 & Ribs right8 & 43.2 \\
\hline 170 & Muscle Sartorius left & 18.6 & 207 & Ribs right 9 & 53.9 \\
\hline 171 & Muscle Sartorius right & 17.5 & 208 & Ribs right 10 & 58.9 \\
\hline 172 & $\begin{array}{l}\text { Muscle Tibialis Anterior } \\
\text { left }\end{array}$ & 6.2 & 209 & Ribs right 11 & 56.9 \\
\hline 173 & $\begin{array}{l}\text { Muscle Tibialis Anterior } \\
\text { right }\end{array}$ & 5.8 & 210 & Ribs right 12 & 40.9 \\
\hline 174 & Muscle Trapezius left & 23.6 & 211 & Sacrum & 45.7 \\
\hline 175 & Muscle Trapezius right & 24.0 & 212 & Scapula left & 38.2 \\
\hline
\end{tabular}




\begin{tabular}{l|l|l|l|l|c}
\hline Mesh & Tissue & $\begin{array}{l}\text { Avg. E field } \\
\text { (V/m RMS) }\end{array}$ & Mesh & Tissue & $\begin{array}{l}\text { Avg. E field } \\
\text { (V/m RMS) }\end{array}$ \\
\hline 176 & Muscle Tricep left & 12.0 & 213 & Scapula right & 38.8 \\
\hline 177 & Muscle Tricep right & 14.0 & 214 & Skin Shell & 27.8 \\
\hline 178 & Navicular left & 1.8 & 215 & Skull & 22.8 \\
\hline 179 & Navicular right & 0.7 & 216 & Sphenoid & 8.9 \\
\hline 180 & Patella left & 24.3 & 217 & Spleen & 33.9 \\
\hline 181 & Patella right & 22.6 & 218 & Sternum & 25.2 \\
\hline 182 & Peripheral Nerve left & 17.1 & 219 & Stomach & 22.6 \\
\hline 183 & Peripheral Nerve Right & 14.1 & 220 & T01 & 28.4 \\
\hline 184 & Pubic Symphysis & 32.1 & 221 & T02 & 27.2 \\
\hline 185 & Radial Nerve left & 14.6 & 222 & T03 & 27.2 \\
\hline 186 & Radial Nerve right & 12.4 & 223 & T04 & 26.9 \\
\hline 187 & Ribs left1 & 26.4 & 224 & T05 & 25.7 \\
\hline 188 & Ribs left2 & 30.1 & 225 & T06 & 25.5 \\
\hline 189 & Ribs left3 & 26.4 & 226 & T07 & 26.2 \\
\hline 190 & Ribs left4 & 26.7 & 227 & T08 & 26.4 \\
\hline 191 & Ribs left5 & 28.3 & 228 & T09 & 26.9 \\
\hline 192 & Ribs left6 & 31.5 & 229 & T10 & 26.1 \\
\hline 193 & Ribs left7 & 37.3 & 230 & T11 & 26.4 \\
\hline 231 & T12 & 27.5 & 240 & Trabecular upper right & 0.9 \\
\hline 232 & Talus left & 1.3 & 241 & Trachea Sinus & 12.4 \\
\hline 233 & Talus right & 0.6 & 242 & Ulna Radius left & 8.1 \\
\hline 234 & Tibia left & 8.3 & 243 & Ulna Radius right & 7.8 \\
\hline 235 & Tibia right & 7.9 & 244 & Uterus & 17.3 \\
\hline 236 & Tongue & 5.2 & 245 & Veins lower & 12.5 \\
\hline 237 & Trabecular lower left & 0.5 & 246 & Veins upper & 12.4 \\
\hline 238 & Trabecular lower right & 0.8 & 247 & White Matter & 1.0 \\
\hline 239 & Trabecular upper left & 0.7 & & & \\
\hline & & & & \\
\hline
\end{tabular}

ICNIRP guidelines. As expected, higher field levels are observed closer to the surface; the field gradually decreases toward the center of the body.

Quantitative estimates of the average electric field for every particular tissue obtained via ANSYS Electromagnetic Suite 18.2.0 are given in Table. 5.3. Note the lower electric fields in the intracranial volume. Additionally, we observe higher electric fields in the individual body muscles. It is also interesting to observe that the fields in bone may be quite high, in particular in the femur and pelvic bones.

However, the computed local electric fields may considerably exceed the values reported in Table 5.3, in particular by 1.5-6 times. These peak values are less accurate. One potential source of the numerical error is insufficient resolution of lengthy and time-consuming full-body computations very close to the interfaces where higher fields are usually observed. 


\subsubsection{SAR Levels}

The body-averaged or whole-body (global-body) $S A R_{\text {body }}$ is given by averaging the local $S A R$ over the entire body volume. In terms of the complex field phasor $\boldsymbol{E}(\boldsymbol{r})$, one has

$$
S A R_{\text {body }}=\frac{1}{V_{\text {body }}} \int_{V_{\text {body }}} \frac{\sigma(\boldsymbol{r})}{2 \rho(\boldsymbol{r})} \boldsymbol{E}(\boldsymbol{r}) \cdot \boldsymbol{E}(\boldsymbol{r})^{*} d V
$$

Here, $\sigma(\boldsymbol{r})$ is the local tissue conductivity and $\rho(\boldsymbol{r})$ is the local mass density. At full power of $3 \mathrm{~kW}$ and positioned at the shoulder landmark, the global-body SAR computed via ANSYS Electromagnetic Suite 18.2 .0 is $0.25 \mathrm{~W} / \mathrm{kg}$. Thus, the total power dissipation in the body does not exceed $30 \mathrm{~W}$, i.e., $1 \%$ of the total power. The same percentage ratio is valid at half input power.

The second critical estimate is $S A R_{1 g}$, which is given by averaging over a contiguous volume with the weight of $1 \mathrm{~g}$,

$$
S A R_{1 g}(\boldsymbol{r})=\frac{1}{V_{1 g}} \int_{V_{1 g}} \frac{\sigma(\boldsymbol{r})}{2 \rho(\boldsymbol{r})} \boldsymbol{E}(\boldsymbol{r}) \cdot \boldsymbol{E}(\boldsymbol{r})^{*} d V
$$

The maximum value of $S A R_{1 g}$ in the body computed via ANSYS Electromagnetic Suite 18.2.0 at the full power of $3 \mathrm{~kW}$ and located at the shoulder landmark is $4.55 \mathrm{~W} / \mathrm{kg}$.

Although this last value might appear to be relatively high, it is still within the corresponding SAR limits in MRI machines [95, 96]. In particular, the major applicable MRI safety standard, issued by the International Electrotechnical Commission (IEC) and also accepted by the U.S. Food and Drug Administration, in the normal mode (mode of operation that causes no physiological stress to patients) limits global-body SAR to $2 \mathrm{~W} / \mathrm{kg}$, global-head SAR to $3.2 \mathrm{~W} / \mathrm{kg}$, local head and torso SAR to $10 \mathrm{~W} / \mathrm{kg}$, and local extremity SAR to $20 \mathrm{~W} / \mathrm{kg}$ [96]. The global SAR limits are intended to ensure a body core temperature of $39^{\circ} \mathrm{C}$ or less $[95,96]$.

\subsection{Discussion}

\subsubsection{Efficacy of Stimulation}

The present study establishes safety and potential feasibility of the resonant neurostimulation device. However, its efficacy for treatment of chronic back pain remains largely unknown. Only clinical trials, which would ideally thoroughly investigate both short-term and cumulative effects of the suggested lower-body electromagnetic treatment, could probably answer this question. Our aim is to provide a doctor 
with the possibility to vary power, resonant frequency, tonic frequency, and electromagnetic pulse envelope to enable the best possible outcome during the anticipated clinical trial.

\subsubsection{Integrated Effect of Stimulation}

The present subthreshold stimulation device will not only affect the PNS of the lower back but also muscles, bones, tendons, and cartilage. Evidence suggests that subthreshold pulsed electromagnetic fields may stimulate osteogenesis in vitro and in vivo [106, 107], improve bone quality in osteoporotic and nonosteoporotic cellbased studies [108, 109], human studies [110-114], animal studies [115-121], and augment bone fracture healing [107, 122-124]. Further evidence suggests that TENS therapy stimulates a change in the biochemical and physiological muscle conditions that may lead to muscle relaxation $[125,126]$. Some evidence also suggests that the $\mathrm{kHz}$ stimulation of the lower body will increase the vascular endothelial growth factor receptor on circulating hematopoietic stem cells [81], whose local niche (the bone marrow of the pelvis, femur, and sternum [127]) might be well affected by the present stimulation device.

Another extremely interesting effect of the $\mathrm{kHz}$ peripheral nerve stimulation observed previously in $[65,80]$ and implicitly in the present device is a potential for sleep improvement. It is not clear how to describe and account these integrated effects of the stimulation. We will attempt to carefully document and report prior relevant literature findings and the corresponding stimulation conditions for nerve/ muscle/bone/marrow, and link them to the present stimulation conditions.

\subsubsection{Operation as an EMAT}

The present electrostimulation device may also operate as an electromagnetic acoustic transducer (EMAT) when a DC current is injected into the tissue via surface electrodes at a specified location. The Lorentz force will excite an ultrasonic field whose frequency is the resonant frequency.

\subsubsection{Variation of Resonant Frequency}

While fine tuning with a low-loss ferromagnetic load is straightforward, it is quite challenging, however, to vary the resonant frequency of a power resonator, which is usually cast in stone, allowing only a narrow tuning range. In order to do this, we have studied three different methods: a bank of electronically controlled switched power capacitors, a bank of fixed capacitors with low-resistance power relay 
switches, and a mechanically replaceable bolted joints-based fixed-capacitor bank. Such banks need be constructed for each of the 144 rungs of the coil in Fig. 5.6 or Fig. 5.7 in order to vary the resonant or carrier frequency over the band of, say, $10-100 \mathrm{kHz}$.

Although the first two approaches are fast and elegant, they are unfeasible. The key is the equivalent series resistance (ESR) of switched capacitors and power relay switches. Existing series switches increase ESR by about 10 times or even more. This dramatically lowers the resonator quality factor $Q$, resulting in about three times lower field values for a given input power. The switched capacitor solution has other serious drawbacks. Each switched capacitor block is much larger than a fixed capacitor, which will result in issues related to physically accommodating all components. On the other hand, for a relay with an exceptionally small contact resistance of $5 \mathrm{~m} \Omega, Q$ will change by a factor of 0.6 at $100 \mathrm{kHz}$ and 0.3 at $10 \mathrm{kHz}$. As the relays cycle, their contact resistance may go up significantly, especially if we do not follow the guidelines for minimum switched current (to create an arc that cleans the contacts). Thus, $Q$ could continue dropping with cycling. Therefore, we plan to implement low-ESR mechanically replaceable bolted-joints based fixed-capacitor banks. The frequency-switching operation will take approximately $3 \mathrm{~h}$.

\subsection{Conclusion}

In this technical study, we described a whole-body noncontact subthreshold electromagnetic stimulation device based on the concept of a familiar MRI RF resonating coil, but at a much lower resonant frequency $(100-150 \mathrm{kHz}$ and potentially down to $10 \mathrm{kHz})$, with a field modulation option $(0.5-100 \mathrm{~Hz})$, and with an input power level of up to $3 \mathrm{~kW}$. Its unique features include a relatively high electric field level within the subject's biological tissue due to the resonant effect but at low power dissipation, or SAR level, in the body itself.

We emphasize that in the low-frequency limit and at moderate field levels, SAR rather weakly correlates with the deposited electric field. One reason for this is that SAR is proportional to the field squared, and is thus quite small at moderate and low field levels. A second reason is that the tissue conductivity itself is lower (at $100 \mathrm{kHz}$, it is twice as low as at $100 \mathrm{MHz}$ for muscle and five times lower for fat [105]).

Due to the large resonator volume and its noncontact nature, the subject may be conveniently located anywhere within the resonating coil over a prolonged period of time at moderate and safe electric field levels. The electric field effect does not depend on a particular body position within the resonator. The field penetration is deep everywhere in the body, including the extremities; muscles, bones, and peripheral tissues are mostly affected. Over a shorter period of time, the electric field levels could be increased to relatively large values with an amplitude of about $1 \mathrm{~V} / \mathrm{cm}$.

We envision treatment of chronic pain, and particularly neuropathic pain, as the primary potential clinical application for the device. The device enables wholebody coverage, which could be useful in the treatment of widespread pain condi- 
tions, such as painful polyneuropathy or fibromyalgia. In addition, a deeper tissue penetration can be achieved without side-effects caused by high current density in the skin associated with the traditional contact electrodes of TENS. It should be noted that these potential clinical applications are speculative and warrant empirical testing in the future.

Considerable attention has been paid to device safety including both the AC power safety and human exposure to electromagnetic fields. In the former case, we have used inductive coupling, which assures that there is no direct current path from the AC power outlet to the coil. This design enhances overall device safety at any power level, including high-power operation. As with more traditional MRI devices, no large metal objects should be located in the immediate vicinity of the coil.

Human exposure to the electromagnetic field within the coil has been evaluated by performing extensive modeling with two independent numerical methods and with an anatomically realistic multi-tissue human phantom. We have shown that the SAR levels within the body correspond to the safety standards of the International Electrotechnical Commission when the input power level of the amplifier driver does not exceed $3 \mathrm{~kW}$. We have also shown that the electric field levels generally comply with the safety standards of the International Commission on Non-Ionizing Radiation Protection when the input power level of the amplifier driver does not exceed $1.5 \mathrm{~kW}$.

Acknowledgments The authors are thankful to Dr. James O'Rourke, Dr. John McNeill, Ms. Leah Morales, Mr. Brandon Weyant (all from Worcester Polytechnic Institute), MD Irina V. Zhdanova (ClockCoach), and Dr. Aapo Nummenmaa (Massachusetts General Hospital) for useful discussions. Dr. Deng is supported by the Intramural Research Program of the National Institute of Mental Health, NIH.

\section{Appendix A: Derivation of Eq. (5.7) and Coil $Q$}

The corresponding measurement circuit is given in Fig. 5.11.

The derivation of Eq. (5.7) is as follows. The coil, when measured at a rung capacitor, looks like a parallel resonator (assuming the two degenerate modes are decoupled). In a narrow band around the high- $Q$ resonance, the parallel resonator impedance can be approximated as:

Fig. 5.11 Measurement circuit to evaluate coil $Q$

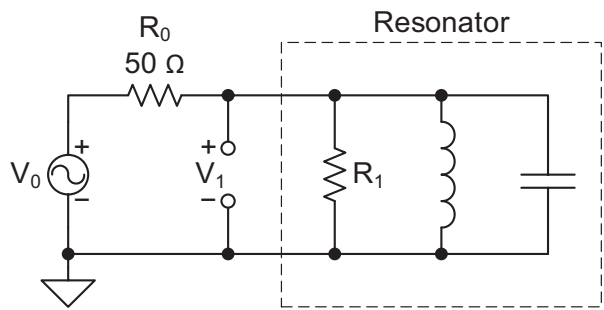




$$
Z_{\text {res }}=\frac{R_{1}}{1+j 2 Q \frac{\Delta f}{f_{0}}}
$$

where $\mathrm{f}_{0}$ is the resonance frequency and $\Delta \mathrm{f}$ is the deviation from it. Then,

$$
\frac{V_{1}}{V_{0}}=\frac{Z_{\text {res }}}{R_{0}+Z_{\text {res }}}
$$

Taking the absolute value and simplifying, one has

$$
\left|\frac{V_{1}}{V_{0}}\right|=\frac{R_{1}}{\sqrt{\left(R_{0}+R_{1}\right)^{2}+4 R_{0}^{2} Q^{2} \frac{\Delta \mathrm{f}^{2}}{f_{0}^{2}}}}
$$

At resonance,

$$
\frac{V_{1}}{V_{0}}=\frac{R_{1}}{R_{0}+R_{1}}
$$

At the $V_{1} 3 \mathrm{~dB}$ frequencies,

$$
\frac{R_{1}}{\sqrt{\left(R_{0}+R_{1}\right)^{2}+4 R_{0}^{2} Q^{2} \frac{\Delta f_{3 \mathrm{~dB}}^{2}}{f_{0}^{2}}}}=\frac{R_{1}}{\sqrt{2}\left(R_{0}+R_{1}\right)}
$$

Solving for $Q$ yields

$$
Q=\frac{f_{0}}{2 \Delta f_{3 \mathrm{~dB}}}\left(\frac{R_{0}+R_{1}}{R_{0}}\right)
$$

From $V_{1} / V_{0}$ at resonance, we can express

$$
1-\frac{V_{1}}{V_{0}}=1-\frac{R_{1}}{R_{0}+R_{1}}=\frac{R_{0}}{R_{0}+R_{1}}
$$

Therefore,

$$
Q=\frac{f_{0}}{2 \Delta f_{3 \mathrm{~dB}}\left(1-\frac{V_{1}}{V_{0}}\right)}
$$


where $V_{1}$ is measured at resonance, and $2 \Delta f_{3 \mathrm{~dB}}=f_{\mathrm{U}}-f_{\mathrm{L}}$, with $\mathrm{f}_{\mathrm{U}}$ and $\mathrm{f}_{\mathrm{L}}$ being the upper and lower $3 \mathrm{~dB}$ frequencies for $V_{1}$.

Regarding the envelope time constant

$$
\tau=\frac{2 Q}{\omega}
$$

we mention that for $Q=300$ and $f=100 \mathrm{kHz}, \tau=0.955 \mathrm{~ms}$. This can be rounded to $1 \mathrm{~ms}$ if high precision is not needed. We do not measure $Q$ through this time constant. It is only mentioned as a limiter of modulation bandwidth.

The quality factor is difficult to predict accurately. Estimated $Q$ from ANSYS HFSS-circuit co-simulation typically comes out about $10-30 \%$ higher than in the real circuit. How much higher depends on the level of refinement of the FEM model. The important parameter is the actual achieved $Q$. ANSYS can still be used for rough coil $Q$ optimization, as long as the level of refinement is kept about the same.

\section{References}

1. The Americian Academy of Pain Medicine. (2011). Relieving pain in America: A blueprint for transforming prevention, care, education, and research. Institute of Medicine. Committee on Advancing Pain Research, Care, and Education. Washington (DC): National Academies Press (US). ISBN 978-0-309-21484-1.

2. The American Academy of Pain Medicine. AAPM Facts and Figures on Pain. Online: http:// www.painmed.org/patientcenter/facts_on_pain.aspx\#america

3. Woolf, C. J. (2011). Central sensitization: implications for the diagnosis and treatment of pain. Pain, 152, S2-S15. https://doi.org/10.1016/j.pain.2010.09.030.

4. Staud, R., Craggs, J. G., Robinson, M. E., Perlstein, W. M., \& Price, D. D. (2007). Brain activity related to temporal summation of C- fiber evoked pain. Pain, 129, 130-142. https:// doi.org/10.1016/j.pain.2006.10.010.

5. Nijs, J., Kosek, E., Van Oosterwijck, J., \& Meeus, M. (2012). Dysfunctional endogenous analgesia during exercise in patients with chronic pain: to exercise or not to exercise? Pain Physician, 1, 205-214.

6. Kuppens, K., Hans, G., Roussel, N., Struyf, F., Fransen, E., Cras, P., Van Wilgen, C. P., \& Nijs, J. (2018). Sensory processing and central pain modulation in patients with chronic shoulder pain: A case-control study. Scandinavian Journal of Medicine \& Science in Sports, 28(3), 1183-1192. https://doi.org/10.1111/sms.12982.

7. Nakamura, M., Nishiwaki, Y., Sumitani, M., Ushida, T., Yamashita, T., Konno, S., Taguchi, T., \& Toyama, Y. (2014). Investigation of chronic musculoskeletal pain (third report): with special reference to the importance of neuropathic pain and psychogenic pain. Journal of Orthopaedic Science, 19(4), 667-675. https://doi.org/10.1007/s00776-014-0567-6.

8. Dunne, F. J., Getachew, H., Cullenbrooke, F., \& Dunne, C. (2018). Pain and pain syndromes. British Journal of Hospital Medicine (London), 79(8), 449-453. https://doi.org/10.12968/ hmed.2018.79.8.449.

9. Lerman, S. F., Rudich, Z., Brill, S., Shalev, H., \& Shahar, G. (2015). Longitudinal associations between depression, anx-iety, pain, and pain-related disability in chronic pain patients. Psychosomatic Medicine, 77(3), 333-341. https://doi.org/10.1097/PSY.0000000000000158.

10. Hall-Flavin DK. Is there a link between pain and depression? Can depression cause physical pain? March 11, 2016. Mayo Clinic. Online: https://www.mayoclinic.org/diseases-conditions/ depression/expert-answers/pain-and-depression/faq-20057823. 
11. Snekkevik, H., Eriksen, H. R., Tangen, T., Chalder, T., \& Reme, S. E. (2014). Fatigue and depression in sick-listed chronic low back pain patients. Pain Medicine, 15(7), 1163-1170. https://doi.org/10.1111/pme.12435.

12. Freburger, J. K., Holmes, G. M., Agans, R. P., Jackman, A. M., Darter, J. D., Wallace, A. S., Castel, L. D., Kalsbeek, W. D., \& Carey, T. S. (2009). The rising prevalence of chronic low back pain. Archives of Internal Medicine, 169(3), 251-258. https://doi.org/10.1001/ archinternmed.2008.543.

13. National Inst. of Neurological Disorders and Stroke. Low back pain fact sheet. 2018-08-07. NIH Publication No. 15-5161.

14. Krath, A., Klüter, T., Stukenberg, M., Zielhardt, P., Gollwitzer, H., Harrasser, N., Hausdorf, J., Ringeisen, M., \& Gerdesmeyer, L. (2017). Electromagnetic transduction therapy in nonspecific low back pain: A prospective randomised controlled trial. Journal of Orthopaedics, 14(3), 410-415. https://doi.org/10.1016/j.jor.2017.06.016.

15. Nayback-Beebe, A. M., Yoder, L. H., Goff, B. J., Arzola, S., \& Weidlich, C. (2017). The effect of pulsed electromagnetic frequency therapy on health-related quality of life in military service members with chronic low back pain. Nursing Outlook, 65(5S), S26-S33. https://doi. org/10.1016/j.outlook.2017.07.012.

16. Outcalt, S. D., Kroenke, K., Krebs, E. E., Chumbler, N. R., Wu, J., Yu, Z., \& Bair, M. J. (2015). Chronic pain and comorbid mental health conditions: Independent associations of posttraumatic stress disorder and depression with pain, disability, and quality of life. Journal of Behavioral Medicine, 38(3), 535-543. https://doi.org/10.1007/s10865-015-9628-3.

17. Alsaadi, S. M., McAuley, J. H., Hush, J. M., \& Maher, C. G. (2011). Prevalence of sleep disturbance in patients with low back pain. European Spine Journal, 20(5), 737-743. https:// doi.org/10.1007/s00586-010-1661-X.

18. Iizuka, Y., Iizuka, H., Mieda, T., Tsunoda, D., Sasaki, T., Tajika, T., Yamamoto, A., \& Takagishi, K. (2017). Prevalence of chronic nonspecific low back pain and its associated factors among middle-aged and elderly people: an analysis based on data from a musculoskeletal examination in Japan. Asian Spine Journal, 11(6), 989-997. https://doi.org/10.4184/ asj.2017.11.6.989.

19. Dworkin, R. H., O’Connor, A. B., Backonja, M., Farrar, J. T., Finnerup, N. B., Jensen, T. S., Kalso, E. A., Loeser, J. D., Miaskowski, C., Nurmikko, T. J., Portenoy, R. K., Rice, A. S., Stacey, B. R., Treede, R. D., Turk, D. C., \& Wallace, M. S. (2007). Pharmacologic management of neuropathic pain: Evidence-based recommendations. Pain, 132(3), 237-251. https:// doi.org/10.1016/j.pain.2007.08.033.

20. Steele, A. (2014). Opioid use and depression in chronic pelvic pain. Obstetrics and Gynecology Clinics of North America, 41(3), 491-501. https://doi.org/10.1016/j.ogc. 2014.04.005.

21. Stanos, S. P., \& Galluzzi, K. E. (2013). Topical therapies in the management of chronic pain. Postgraduate Medicine, 125(4 Suppl 1), 25-33. https://doi.org/10.1080/00325481.2013.111 0567111.

22. Johnson MI, Claydon LS, Herbison GP, Jones G, and Paley CA. Transcutaneous electrical nerve stimulation (TENS) for fibromyalgia in adults. Cochrane Database of Systematic Reviews 2017, Issue 10. Art. No.:CD012172. doi: https://doi.org/10.1002/14651858. CD012172.pub2.

23. Gibson W, Wand BM, O'Connell NE. Transcutaneous electrical nerve stimulation (TENS) for neuropathic pain in adults. Cochrane Database of Systematic Reviews 2017, Issue 9. Art. No.: CD011976. doi: https://doi.org/10.1002/14651858.CD011976.pub2.

24. Koca, I., Boyaci, A., Tutoglu, A., Ucar, M., \& Kocaturk, O. (2014). Assessment of the effectiveness of interferential current therapy and TENS in the management of carpal tunnel syndrome: a randomized controlled study. Rheumatology International, 34, 1639-1645. https:// doi.org/10.1007/s00296-014-3005-3.

25. Brosseau, L., Judd, M. G., Marchand, S., Robinson, V. A., Tugwell, P., Wells, G., \& Younge, K. (2003). Transcutaneous electrical nerve stimulation (TENS) for the treatment of rheumatoid arthritis in the hand. Cochrane Database of Systematic Reviews, (3). https://doi. org/10.1002/14651858.CD004287.pub2. 
26. Khadilkar, A., Odebiyi, D. O., Brosseau, L., \& Wells, G. A. (2008). Transcutaneous electrical nerve stimulation (TENS) versus placebo for chronic low-back pain. Cochrane Database of Systematic Reviews, (4). https://doi.org/10.1002/14651858.CD003008.pub3.

27. Dowswell, C., Bedwell, C., Lavender, T., \& Neilson, J. P. (2009). Transcutaneous electrical nerve stimulation (TENS) for pain management in labour. Cochrane Database of Systematic Reviews, (2). https://doi.org/10.1002/14651858.CD007214.pub2.

28. Johnson, M. I., Mulvey, M. R., \& Bagnall, A. M. (2015). Transcutaneous electrical nerve stimulation (TENS) for phantom pain and stump pain following amputation in adults. Cochrane Database of Systematic Reviews, (8). https://doi.org/10.1002/14651858.CD007264.pub3.

29. Makarov, S. N., Bogdanov, G., Makarov, V. S., Noetscher, G. M., \& Deng, Z-D. (2018). A whole body non-contact electrical stimulation device with variable parameters. US Patent Application \#15868038 of Jan. 11 ${ }^{\text {th }}$ 2018. Pub \# 20180196113; Pub Date July $12^{\text {th }} 2018$. Revision Oct 2018.

30. Makarov, S. N., Bogdanov, G., Noetscher, G. M., Allpleyard, W., Ludwig, R., Joutsa, U. T., \& Deng, Z.-D. (2018). Design and analysis of a whole body non-contact electromagnetic stimulation device with field modulation at low and medium power levels. bioRxiv, 416065. https://doi.org/10.1101/416065.

31. InTENSity ${ }^{\mathrm{TM}}$ Twin Stim ${ }^{\circledR}$ III Datasheet. Current Solutions, LLC, Austin, TX. Online: https:// www.tenspros.com/assets/images/manuals/InTENSity-Twin-Stim-III-di3717-Manual.pdf

32. TENS (transcutaneous electrical nerve stimulation). National Health Service (NHS) in England. 08/10/2018. Online: https://www.nhs.uk/conditions/transcutaneous-electricalnerve-stimulation-tens/

33. Schmerzen lindern ohne Pillen: Elektrotherapie. NDR.de - Ratgeber - Gesundheit. Online: https://www.ndr.de/ratgeber/gesundheit/index.html

34. Leung, A., Fallah, A., \& Shukla, S. (2014). Transcutaneous magnetic stimulation (TMS) in alleviating post-traumatic peripheral neuropathic pain states: a case series. Pain Medicine, 15(7), 1196-1199. https://doi.org/10.1111/pme.12426.

35. Leung, A., Shukla, S., Lee, J., Metzger-Smith, V., He, Y., \& Chen, J. (2015). Golshan. Effect of low frequency transcutaneous magnetic stimulation on sensory and motor transmission. Bioelectromagnetics, 36(6), 410-419. https://doi.org/10.1002/bem.21921.

36. O'Reardon, J. P., Solvason, H. B., Janicak, P. G., Sampson, S., Isenberg, K. E., Nahas, Z., McDonald, W. M., Avery, D., Fitzgerald, P. B., Loo, C., Demitrack, M. A., George, M. S., \& Sackeim, H. A. (2007). Efficacy and safety of transcranial magnetic stimulation in the acute treatment of major depression: a multisite randomized controlled trial. Biological Psychiatry, 62(11), 1208-1216. https://doi.org/10.1016/j.biopsych.2007.01.018.

37. Bajbouj, M., Merkl, A., Schlaepfer, T. E., Frick, C., Zobel, A., Maier, W., O'Keane, V., Corcoran, C., Adolfsson, R., Trimble, M., Rau, H., Hoff, H. J., Padberg, F., MüllerSiecheneder, F., Audenaert, K., van den Abbeele, D., Matthews, K., Christmas, D., Eljamel, S., \& Heuser, I. (2010). Two-year outcome of vagus nerve stimulation in treatmentresistant depression. Journal of Clinical Psychopharmacology, 30(3), 273-281. https://doi. org/10.1097/JCP.0b013e3181db8831.

38. Trevino, K., McClintock, S. M., \& Husain, M. M. (2010). A review of continuation electroconvulsive therapy: application, safety, and efficacy. The Journal of ECT, 26(3), 186-195. https://doi.org/10.1097/YCT.0b013e3181efa1b2.

39. Chakraborty, D., Truong, D. Q., Bikson, M., \& Kaphzan, H. (2018). Neuromodulation of axon terminals. Cerebral Cortex, 28(8), 2786-2794. https://doi.org/10.1093/cercor/bhx158.

40. Jefferys, J. G. (1981). Influence of electric fields on the excitability of granule cells in guineapig hippocampal slices. The Journal of Physiology, 319, 143-152.

41. Bikson, M., Inoue, M., Akiyama, H., Deans, J. K., Fox, J. E., Miyakawa, H., \& Jefferys, J. G. R. (2004). Effects of uniform extracellular DC electric fields on excitability in rat hippocampal slices in vitro. The Journal of Physiology, 557.(Pt 1, 175-190. https://doi.org/10.1113/ jphysiol.2003.055772.

42. Rahman, A., Reato, D., Arlotti, M., Gasca, F., Datta, A., Parra, L. C., \& Bikson, M. (2013). 2013. Cellular effects of acute direct current stimulation: somatic and synaptic 
terminal effects. The Journal of Physiology, 591(10), 2563-2578. https://doi.org/10.1113/ jphysiol.2012.247171.

43. Kerezoudis, P., Grewal, S. S., Stead, M., Lundstrom, B. N., Britton, J. W., Shin, C., Cascino, G. D., Brinkmann, B. H., Worrell, G. A., \& Van Gompel, J. J. (2018). Chronic subthreshold cortical stimulation for adult drug-resistant focal epilepsy: safety, feasibility, and technique. Journal of Neurosurgery, 129(2), 533-543. https://doi.org/10.3171/2017.5.JNS163134.

44. Stagg, C. J., Antal, A., \& Nitsche, M. A. (2018). Physiology of transcranial direct current stimulation. The Journal of ECT, 34(3), 144-152. https://doi.org/10.1097/ YCT.0000000000000510.

45. Aspart, F., Remme, M. W. H., \& Obermayer, K. (2018). Differential polarization of cortical pyramidal neuron dendrites through weak extracellular fields. PLoS Computational Biology, 14(5), e1006124. https://doi.org/10.1371/journal.pcbi.1006124.

46. Toloza, E. H. S., Negahbani, E., \& Fröhlich, F. (2018). LH interacts with somato-dendritic structure to determine frequency response to weak alternating electric field stimulation. Journal of Neurophysiology, 119(3), 1029-1036. https://doi.org/10.1152/jn.00541.2017.

47. Khatoun, A., Asamoah, B., \& Mc Laughlin, M. (2017). Simultaneously excitatory and inhibitory effects of transcranial alternating current stimulation revealed using selective pulse-train stimulation in the rat motor cortex. The Journal of Neuroscience, 37(39), 9389-9402. https:// doi.org/10.1523/JNEUROSCI.1390-17.2017.

48. Fava, M., Freeman, M. P., Flynn, M., Hoeppner, B. B., Shelton, R., Iosifescu, D. V., Murrough, J. W., Mischoulon, D., Cusin, C., Rapaport, M., Dunlop, B. W., Trivedi, M. H., Jha, M., Sanacora, G., Hermes, G., \& Papakostas, G. I. (2018). Double-blind, proof-of-concept (POC) trial of low-field magnetic stimulation (LFMS) augmentation of antidepressant therapy in treatment-resistant depression (TRD). Brain Stimulation, 11(1), 75-84. https://doi. org/10.1016/j.brs.2017.09.010.

49. Rohan, M., Parow, A., Stoll, A. L., Demopulos, C., Friedman, S., Dager, S., Hennen, J., Cohen, B. M., \& Renshaw, P. F. (2004). Low-field magnetic stimulation in bipolar depression using an MRI-based stimulator. The American Journal of Psychiatry, 161(1), 93-98. https:// doi.org/10.1176/appi.ajp.161.1.93.

50. Rohan, M. L., Yamamoto, R. T., Ravichandran, C. T., Cayetano, K. R., Morales, O. G., Olson, D. P., Vitaliano, G., Paul, S. M., \& Cohen, B. M. (2014). Rapid mood-elevating effects of low field magnetic stimulation in depression. Biological Psychiatry, 76(3), 186-193. https://doi. org/10.1016/j.biopsych.2013.10.024.

51. Carlezon, W. A., Rohan, M. L., Mague, S. D., Meloni, E. G., Parsegian, A., Cayetano, K., Tomasiewicz, H. C., Rouse, E. D., Cohen, B. M., \& Renshaw, P. F. (2005). Antidepressantlike effects of cranial stimulation within a low-energy magnetic field in rats. Biological Psychiatry, 57, 571-576. https://doi.org/10.1016/j.biopsych.2004.12.011.

52. Aksoz, E., Aksoz, T., Bilge, S. S., Ilkaya, F., Celik, S., \& Diren, H. B. (2008). Antidepressantlike effects of echo-planar magnetic resonance imaging in mice determined using the forced swimming test. Brain Research, 1236, 191-196. https://doi.org/10.1016/j. brainres.2008.08.011.

53. Rokni-Yazdi, H., Sotoudeh, H., Akhondzadeh, S., Sotoudeh, E., Asadi, H., \& Shakiba, M. (2007). Antidepressant-like effect of magnetic resonance imaging-based stimulation in mice. Progress in Neuro-Psychopharmacology \& Biological Psychiatry, 31, 503-509. https://doi. org/10.1016/j.pnpbp.2006.11.021.

54. Volkow, N. D., Tomasi, D., Wang, G. J., Fowler, J. S., Telang, F., Wang, R., Alexoff, D., Logan, J., Wong, C., Pradhan, K., Caparelli, E. C., Ma, Y., \& Jayne, M. (2010). Effects of low-field magnetic stimulation on brain metabolism. NeuroImage, 51, 623-628. https://doi. org/10.1016/j.neuroimage.2010.02.015.

55. Shamji, M. F., De Vos, C., \& Sharan, A. (2017). The advancing role of neuromodulation for the management of chronic treatment-refractory pain. Neurosurgery, 80(3S), S108-S113. https://doi.org/10.1093/neuros/nyw047.

56. Pelot, N. A., Behrend, C. E., \& Grill, W. M. (2017). Modeling the response of small myelinated axons in a compound nerve to kilohertz frequency signals. Journal of Neural Engineering, 14(4), 046022. https://doi.org/10.1088/1741-2552/aa6a5f. 
57. Provenzano, D. A., Rebman, J., Kuhel, C., Trenz, H., \& Kilgore, J. (2017). The efficacy of high-density spinal cord stimulation among trial, implant, and conversion patients: A retrospective case series. Neuromodulation, 20(7), 654-660. https://doi.org/10.1111/ner.12612.

58. De Jaeger, M., van Hooff, R. J., Goudman, L., Valenzuela Espinoza, A., Brouns, R., Puylaert, M., Duyvendak, W., \& Moens, M. (2017). High-density in spinal cord stimulation: virtual expert registry (DISCOVER): Study protocol for a prospective observational trial. Anesthesiology and Pain Medicine, 7(3), e13640. https://doi.org/10.5812/aapm.13640.

59. Al-Kaisy, A., Palmisani, S., Pang, D., Sanderson, K., Wesley, S., Tan, Y., McCammon, S., \& Trescott, A. (2018). Prospective, randomized, sham-control, double blind, crossover trial of subthreshold spinal cord stimulation at various kilohertz frequencies in subjects suffering from failed back surgery syndrome (SCS frequency study). Neuromodulation, 21(5), 457465. https://doi.org/10.1111/ner.12771.

60. Zhang, L., Lu, Y., Sun, J., Zhou, X., \& Tang, B. (2016). Subthreshold vagal stimulation suppresses ventricular arrhythmia and inflammatory response in a canine model of acute cardiac ischaemia and reperfusion. Experimental Physiology, 101(1), 41-49. https://doi.org/10.1113/ EP085518.

61. Slotty, P. J., Bara, G., Kowatz, L., Gendolla, A., Wille, C., Schu, S., \& Vesper, J. (2015). Occipital nerve stimulation for chronic migraine: a randomized trial on subthreshold stimulation. Cephalalgia, 35(1), 73-78. https://doi.org/10.1177/0333102414534082.

62. Zheng, Y., \& Hu, X. (2018). Reduced muscle fatigue using kilohertz-frequency subthreshold stimulation of the proximal nerve. Journal of Neural Engineering. https://doi. org/10.1088/1741-2552/aadecc.

63. Hotta, H., Onda, A., Suzuki, H., Milliken, P., \& Sridhar, A. (2017). Modulation of calcitonin, parathyroid hormone, and thyroid hormone secretion by electrical stimulation of sympathetic and parasympathetic nerves in anesthetized rats. Frontiers in Neuroscience, 11, 375. https:// doi.org/10.3389/fnins.2017.00375.

64. Vargas Luna, J. L., Mayr, W., \& Cortés-Ramirez, J. A. (2018). Sub-threshold depolarizing prepulses can enhance the efficiency of biphasic stimuli in transcutaneous neuromuscular electrical stimulation. Medical \& Biological Engineering \& Computing. https://doi. org/10.1007/s11517-018-1851-y.

65. Gulyaev, Y. V., Bugaev, A. S., Indursky, P. A., Shakhnarovich, V. M., \& Dementienko, V. V. (2017). Improvement of the night sleep quality by electrocutaneous subthreshold stimulation synchronized with the slow wave sleep. Doklady Biological Sciences, 474(1), 132-134. https://doi.org/10.1134/S0012496617030139.

66. Makarov, S. N., Noetscher, G. M., \& Nazarian, A. (2015). A low-frequency electromagnetic modeling for electrical and biological systems using MATLAB. New York: Wiley.

67. Hayes, C. E., Edelstein, W. A., Schenck, J. F., Mueller, O. M., \& Eash, M. (1985). An efficient, highly homogeneous radiofrequency coil for whole-body NMR imaging at $1.5 \mathrm{~T}$. Journal of Magnetic Resonance, 63, 622-628. https://doi.org/10.1016/0022-2364(85)90257-4.

68. Hayes, C. E. (2009). The development of the birdcage resonator: A historical perspective. NMR in Biomedicine, 22, 908-918. https://doi.org/10.1002/nbm.1431.

69. Lempka, S. F., McIntyre, C. C., Kilgore, K. L., \& Machado, A. G. (2015 Jun). Computational analysis of kilohertz frequency spinal cord stimulation for chronic pain management. Anesthesiology, 122(6), 1362-1376. https://doi.org/10.1097/ALN.0000000000000649.

70. Reddy, C. G., Dalm, B. D., Flouty, O. E., Gillies, G. T., Howard, M. A., \& Brennan, T. J. (2016). Comparison of conventional and kilohertz frequency epidural stimulation in patients undergoing trialing for spinal cord stimulation: clinical considerations. World Neurosurgery, 88, 586-591. https://doi.org/10.1016/j.wneu.2015.10.088.

71. Shechter, R., Yang, F., Xu, Q., Cheong, Y. K., He, S. Q., Sdrulla, A., Carteret, A. F., Wacnik, P. W., Dong, X., Meyer, R. A., Raja, S. N., \& Guan, Y. (2013). Conventional and kilohertzfrequency spinal cord stimulation produces intensity- and frequency-dependent inhibition of mechanical hypersensitivity in a rat model of neuropathic pain. Anesthesiology, 119(2), 422-432. https://doi.org/10.1097/ALN.0b013e31829bd9e2.

72. Thomson, S. J., Tavakkolizadeh, M., Love-Jones, S., Patel, N. K., Gu, J. W., Bains, A., Doan, Q., \& Moffitt, M. (2018). Effects of rate on analgesia in kilohertz frequency spinal cord stim- 
ulation: Results of the proco randomized controlled trial. Neuromodulation, 21(1), 67-76. https://doi.org/10.1111/ner.12746.

73. Billet, B., Wynendaele, R., \& Vanquathem, N. E. (2017). Wireless neuromodulation for chronic back pain: delivery of high frequency dorsal root ganglion stimulation by a minimally invasive technique. Case Reports in Medicine, 2017, 4203271. https://doi. org/10.1155/2017/4203271.

74. Huygen, F., Liem, L., Cusack, W., \& Kramer, J. (2018). Stimulation of the L2-L3 dorsal root ganglia induces effective pain relief in the low back. Pain Practice, 18(2), 205-213. https:// doi.org/10.1111/papr.12591.

75. Simopoulos, T., Yong, R. J., \& Gill, J. S. (2018). Treatment of chronic refractory neuropathic pelvic pain with high-frequency 10-kilohertz spinal cord stimulation. Pain Practice, 18(6), 805-809. https://doi.org/10.1111/papr.12656.

76. Haider, N., Ligham, D., Quave, B., Harum, K. E., Garcia, E. A., Gilmore, C. A., Miller, N., Moore, G. A., Bains, A., Lechleiter, K., \& Jain, R. (2018). Spinal cord stimulation (SCS) trial outcomes after conversion to a multiple waveform SCS system. Neuromodulation, 21(5), 504-507. https://doi.org/10.1111/ner.12783.

77. Amirdelfan, K., Yu, C., Doust, M. W., Gliner, B. E., Morgan, D. M., Kapural, L., Vallejo, R., Sitzman, B. T., Yearwood, T. L., Bundschu, R., Yang, T., Benyamin, R., Burgher, A. H., Brooks, E. S., Powell, A. A., \& Subbaroyan, J. (2018). Long-term quality of life improvement for chronic intractable back and leg pain patients using spinal cord stimulation: 12-month results from the SENZA-RCT. Quality of Life Research, 27(8), 2035-2044. https://doi. org/10.1007/s11136-018-1890-8.

78. Kim, Y., Cho, H. J., \& Park, H. S. (2018). Technical development of transcutaneous electrical nerve inhibition using medium-frequency alternating current. Journal of Neuroengineering and Rehabilitation, 15(1), 80. https://doi.org/10.1186/s12984-018-0421-8.

79. Reichstein, L., Labrenz, S., Ziegler, D., \& Martin, S. (2005). Effective treatment of symptomatic diabetic polyneuropathy by high-frequency external muscle stimulation. Diabetologia, 48(5), 824-828. https://doi.org/10.1007/s00125-005-1728-0.

80. Humpert, P. M., Morcos, M., Oikonomou, D., Schaefer, K., Hamann, A., Bierhaus, A., Schilling, T., \& Nawroth, P. P. (2009). External electric muscle stimulation improves burning sensations and sleeping disturbances in patients with type 2 diabetes and symptomatic neuropathy. Pain Medicine, 10(2), 413-419. https://doi.org/10.1111/j.1526-4637.2008.00557.x.

81. Hidmark, A., Spanidis, I., Fleming, T. H., Volk, N., Eckstein, V., Groener, J. B., Kopf, S., Nawroth, P. P., \& Oikonomou, D. (2017). Electrical muscle stimulation induces an increase of VEGFR2 on circulating hematopoietic stem cells in patients with diabetes. Clinical Therapeutics, 39(6), 1132-1144.e2. https://doi.org/10.1016/j.clinthera.2017.05.340.

82. The HiToP® Models 184-191: Polyneuropathy high frequency stimulator. gbo Medizintechnik AG, Rimbach, Germany, Online: https://www.gbo-med.de/pnp.html

83. Borsboom, H. M., Claasen-Vujcic, T., Gaykema, H. J. G., \& Mehlkopf, T. (1997). Lowfrequency quadrature mode birdcage resonator. Magma, 5(1), 33-37.

84. Claasen-Vujcic, T., Borsboom, H. M., Gaykema, H. J. G., \& Mehlkopf, T. (1996). Transverse low-field RF coils in MRI transverse low-field RF coils in MRI. Magnetic Resonance in Medicine, 36(1), 111-116.

85. Galante, A., Sinibaldi, R., Conti, A., De Luca, C., Catallo, N., Sebastiani, P., Pizzella, V., Romani, G. L., Sotgiu, A., \& Della Penna, S. (2015). Fast room temperature very low fieldmagnetic resonance imaging system compatible with magnetoencephalography environment. PLoS One, 10(12), e0142701. https://doi.org/10.1371/journal.pone.0142701.

86. Savukov, I., Karaulanov, T., Castro, A., Volegov, P., Matlashov, A., Urbatis, A., Gomez, J., \& Espy, M. (2011). Non-cryogenic anatomical imaging in ultra-low field regime: Hand MRI demonstration. Journal of Magnetic Resonance, 211(2), 101-108. https://doi.org/10.1016/j. jmr.2011.05.011.

87. Tsai, L. L., Mair, R. W., Rosen, M. S., Patz, S., \& Walsworth, R. L. (2008). An open-access, very-low-field MRI system for posture-dependent $3 \mathrm{He}$ human lung imaging. Journal of Magnetic Resonance, 193(2), 274-285. https://doi.org/10.1016/j.jmr.2008.05.016. 
88. Kuzmin, V. V., Bidinosti, C. P., Hayden, M. E., \& Nacher, P. J. (2015). An improved shielded RF transmit coil for low-frequency NMR and MRI. Journal of Magnetic Resonance, 256, 70-76. https://doi.org/10.1016/j.jmr.2015.05.001.

89. Makarov, S., Noetscher, G. M., Raij, T., \& Nummenmaa, A. (2018). A quasi-static boundary element approach with fast multipole acceleration for high-resolution bioelectromagnetic models. IEEE Transactions on Biomedical Engineering. https://doi.org/10.1109/ TBME.2018.2813261.

90. Smythe, W. R. (1950). Static and dynamic electricity (2nd ed.). New York: McGraw-Hill.

91. International Commission on Non-Ionizing Radiation Protection. (2010). Guidelines for limiting exposure to time-varying electric and magnetic fields $(1 \mathrm{~Hz}$ to $100 \mathrm{kHz}$ ). Health Physics Society. https://doi.org/10.1097/HP.0b013e3181f06c86.

92. Zhang, B., Yen, Y. F., Chronik, B. A., McKinnon, G. C., Schaefer, D. J., \& Rutt, B. K. (2003). Peripheral nerve stimulation properties of head and body gradient coils of various sizes. Magnetic Resonance in Medicine, 50(1), 50-58. https://doi.org/10.1002/mrm.10508.

93. Davids, M., Guérin, B., Schad, L. R., \& Wald, L. L. (2017). Predicting magneto-stimulation thresholds in the peripheral nervous system using realistic body models. Scientific Reports, 7, 5316. https://doi.org/10.1038/s41598-017-05493-9.

94. Davids, M., Guérin, B., Vom Endt, A., Schad, L. R., \& Wald, L. L. (2018). Prediction of peripheral nerve stimulation thresholds of MRI gradient coils using coupled electromagnetic and neurodynamic simulations. Magnetic Resonance in Medicine. https://doi.org/10.1002/ mrm.27382.

95. International Electrotechnical Commission. (2010). International standard, Medical equipment - IEC 60601-2-33: Particular requirements for the safety of magnetic resonance equipment, 3rd Ed., Amendment 1 (2013), Amendment 2 (2015). Online: https://webstore.iec.ch/ publication $/ 22705$

96. Homann, H. (2012). SAR prediction and SAR management for parallel transmit MRI. Karlsruhe Translations on Biomedical Engineering, 16, 1-124.

97. Makarov, S. N., Noetscher, G. M., Yanamadala, J., Piazza, M. W., Louie, S., Prokop, A., Nazarian, A., \& Nummenmaa, A. (2017). Virtual human models for electromagnetic studies and their applications. IEEE Reviews in Biomedical Engineering, 10, 95-121. https://doi. org/10.1109/RBME.2017.2722420.

98. Makarov, S. N., Yanamadala, J., Piazza, M. W., Helderman, A. M., Thang, N. S., Burnham, E. H., \& Pascual-Leone, A. (2016). Preliminary upper estimate of peak currents in transcranial magnetic stimulation at distant locations from a TMS coil. IEEE Transactions on Biomedical Engineering, 63(9), 1944-1955. https://doi.org/10.1109/TBME.2015.2507572.

99. Kozlov, M., Tankaria, H., Noetscher, G. M., \& Makarov, S. N. (2017). Comparative analysis of different versions of a human model located inside a 1.5T MRI whole body RF coil. Conference Proceedings: Annual International Conference of the IEEE Engineering in Medicine and Biology Society, 2017, 1477-1480. https://doi.org/10.1109/EMBC.2017.8037114.

100. Tran, A. L., \& Makarov, S. N. (2017). Degree of RF MRI coil detuning for an anatomically realistic respiratory cycle modeled with the finite element method. Conference Proceedings: Annual International Conference of the IEEE Engineering in Medicine and Biology Society, 2017, 1405-1408. https://doi.org/10.1109/EMBC.2017.8037096.

101. Noetscher, G. M., Yanamadala, J., Tankaria, H., Louie, S., Prokop, A., Nazarian, A., \& Makarov, S. N. (2016). Computational human model VHP-FEMALE derived from datasets of the National Library of Medicine. Conference Proceedings: Annual International Conference of the IEEE Engineering in Medicine and Biology Society, 2016, 3350-3353. https://doi.org/10.1109/EMBC.2016.7591445.

102. Tankaria, H., Jackson, X. J., Borwankar, R., Srichandhru, G. N., Le Tran, A., Yanamadala, J., Noetscher, G. M., Nazarian, A., Louie, S., \& Makarov, S. N. (2016). VHP-Female full-body human CAD model for cross-platform FEM simulations: recent development and validations. Conference Proceedings: Annual International Conference of the IEEE Engineering in Medicine and Biology Society, 2016, 2232-2235. https://doi.org/10.1109/ EMBC.2016.7591173. 
103. Yanamadala, J., Noetscher, G. M., Rathi, V. K., Maliye, S., Win, H. A., Tran, A. L., Jackson, X. J., Htet, A. T., Kozlov, M., Nazarian, A., Louie, S., \& Makarov, S. N. (2015). New VHP-Female v. 2.0 full-body computational phantom and its performance metrics using FEM simulator ANSYS HFSS. Conference Proceedings: Annual International Conference of the IEEE Engineering in Medicine and Biology Society, 2015, 3237-3241. https://doi. org/10.1109/EMBC.2015.7319082.

104. U.S. National Library of Medicine. The Visible Human Project@ Online: http://www.nlm. nih.gov/research/visible/visible_human.html

105. Hasgall PA, Neufeld E, Gosselin MC, Klingenböck A, Kuster N, Klingenbock A, et al. 2015 IT'IS Database for thermal and electromagnetic parameters of biological tissues. Online: www.itis.ethz.ch/database.

106. Tsai, M. T., Li, W. J., Tuan, R. S., \& Chang, W. H. (2009). Modulation of osteogenesis in human mesenchymal stem cells by specific pulsed electromagnetic field stimulation. Journal of Orthopaedic Research, 27, 1169-1174. https://doi.org/10.1002/jor.20862.

107. Assiotis, A., Chalidis, B. E., \& Sachinis, N. P. (2012 Jun 8). Pulsed electromagnetic fields for the treatment of tibial delayed unions and nonunions. A prospective clinical study and review of the literature. Journal of Orthopaedic Surgery and Research, 7, 24. https://doi. org/10.1186/1749-799X-7-24.

108. Wu, S., Yu, Q., Sun, Y., \& Tian, J. (2018). Synergistic effect of a LPEMF and SPIONs on BMMSC proliferation, directional migration, and osteoblastogenesis. American Journal of Translational Research, 10(5), 1431-1443.

109. Ehnert, S., Fentz, A. K., Schreiner, A., Birk, J., Wilbrand, B., Ziegler, P., Reumann, M. K., Wang, H., Falldorf, K., \& Nussler, A. K. (2017). Extremely low frequency pulsed electromagnetic fields cause antioxidative defense mechanisms in human osteoblasts via induction of O2- and H2O2. Scientific Reports, 7(1), 14544. https://doi.org/10.1038/s41598-017-14983-9.

110. Li, S., Jiang, H., Wang, B., Gu, M., Bi, X., Yin, Y., \& Wang, Y. (2018). Magnetic resonance spectroscopy for evaluating the effect of pulsed electromagnetic fields on marrow adiposity in postmenopausal women with osteopenia. Journal of Computer Assisted Tomography. https:// doi.org/10.1097/RCT.0000000000000757.

111. Ashraf, A. M., Abdelaal, P. D., Mona, M. T., Doaa, I. A., \& Amira, H. D. (2017). Effect of pulsed electromagnetic therapy versus low-level laser therapy on bone mineral density in the elderly with primary osteoporosis: a randomized, controlled trial. Bulletin of Faculty of Physical Therapy, 22(1), 34-39.

112. Yuan, J., Xin, F., \& Jiang, W. (2018). Underlying signaling pathways and therapeutic applications of pulsed electromagnetic fields in bone repair. Cellular Physiology and Biochemistry, 46(4), 1581-1594. https://doi.org/10.1159/000489206.

113. Woods, B., Manca, A., Weatherly, H., Saramago, P., Sideris, E., Giannopoulou, C., Rice, S., Corbett, M., Vickers, A., Bowes, M., MacPherson, H., \& Sculpher, M. (2017). Cost-effectiveness of adjunct non-pharmacological interventions for osteoarthritis of the knee. PLoS One, 12(3), e0172749. https://doi.org/10.1371/journal.pone.0172749.

114. Bilgin, H. M., Çelik, F., Gem, M., Akpolat, V., Yıldız, İ., Ekinci, A., Özerdem, M. S., \& Tunik, S. (2017). Effects of local vibration and pulsed electromagnetic field on bone fracture: A comparative study. Bioelectromagnetics, 38(5), 339-348. https://doi.org/10.1002/ bem. 22043.

115. Sert, C., Mustafa, D., Düz, M. Z., Akşen, F., \& Kaya, A. (2002). The preventive effect on bone loss of 50-Hz, 1-mT electromagnetic field in ovariectomized rats. Journal of Bone and Mineral Metabolism, 20, 345-349. https://doi.org/10.1007/s007740200050.

116. Chang, K., \& Chang, W. H. S. (2003). Pulsed electromagnetic fields prevent osteoporosis in an ovariectomized female rat model: A prostaglandin E2-associated process. Bioelectromagnetics, 24, 189-198. https://doi.org/10.1002/bem.10078.

117. Jing, D., Cai, J., Shen, G., Huang, J., Li, F., Li, J., Lu, L., Luo, E., \& Xu, Q. (2011). The preventive effects of pulsed electromagnetic fields on diabetic bone loss in streptozotocin-treated rats. Osteoporosis International, 22, 1885-1895. https://doi.org/10.1007/s00198-010-1447-3. 
118. Jing, D., Cai, J., Wu, Y., Shen, G., Li, F., Xu, Q., Xie, K., Tang, C., Liu, J., Guo, W., Wu, X., Jiang, M., \& Luo, E. (2014). Pulsed electromagnetic fields partially preserve bone mass, microarchitecture, and strength by promoting bone formation in hindlimb-suspended rats. Journal of Bone and Mineral Research, 29, 2250-2261. https://doi.org/10.1002/jbmr.2260.

119. Lei, T., Li, F., Liang, Z., Tang, C., Xie, K., Wang, P., Dong, X., Shan, S., Liu, J., Xu, Q., Luo, E., \& Shen, G. Effects of four kinds of electromagnetic fields (EMF) with different frequency spectrum bands on ovariectomized osteoporosis in mice. Scientific Reports, 7(1), 553. https:// doi.org/10.1038/s41598-017-00668-w.

120. Li, J., Zeng, Z., Zhao, Y., Jing, D., Tang, C., Ding, Y., \& Feng, X. Effects of low-intensity pulsed electromagnetic fields on bone microarchitecture, mechanical strength and bone turnover in type 2 diabetic db/db mice. Scientific Reports, 7, 10834. https://doi.org/10.1038/ s41598-017-11090-7.

121. Aksoy, M. Ç., Topal, O., Özkavak, H. V., Doğuç, D. K., Ilhan, A. A., \& Çömlekçi, S. (2017). Effects of pulsed electromagnetic field on mineral density, biomechanical properties, and metabolism of bone tissue in heparin-induced osteoporosis in male rats. Biomedical Research, 28(6), 2724-2729.

122. Andrew, C., Bassett, C. A., Pawluk, R. J., \& Pilla, A. A. (1974). Augmentation of bone repair by inductively coupled electromagnetic fields. Science, 184, 575-577.

123. Bassett, C. A., Mitchell, S. N., \& Gasto, S. R. (1982). Pulsing electromagnetic field treatment in ununited fractures and failed arthrodeses. Journal of the American Medical Association (JAMA), 247, 623-628.

124. Tabrah, F., Hoffmeier, M., Gilbert, F., Batkin, S., \& Bassett, C. A. (1990). Bone density changes in osteoporosis-prone women exposed to pulsed electromagnetic fields (PEMFs). Journal of Bone and Mineral Research, 5, 437-442. https://doi.org/10.1002/jbmr.5650050504.

125. Ramos, L. A. V., Callegari, B., França, F. J. R., Magalhães, M. O., Burke, T. N., Carvalho E Silva, A. P. M. C., Almeida, G. P. L., Comachio, J., \& Marques, A. P. (2018). Comparison between transcutaneous electrical nerve stimulation and stabilization exercises in fatigue and transversus abdominis activation in patients with lumbar disk herniation: A randomized study. Journal of Manipulative and Physiological Therapeutics, 41(4), 323-331. https://doi. org/10.1016/j.jmpt.2017.10.010.

126. Namuun, G., Endo, Y., Abe, Y., Nakazawa, R., \& Sakamoto, M. (2012). The effect of muscle fatigue using short term transcutaneous electrical nerve stimulation. Journal of Physical Therapy Science, 24(5), 373-377. https://doi.org/10.1589/jpts.24.373.

127. Morrison, S. J., \& Scadden, D. T. (2014). The bone marrow niche for haematopoietic stem cells. Nature, 505(7483), 327-334. https://doi.org/10.1038/nature12984.

Open Access This chapter is licensed under the terms of the Creative Commons Attribution 4.0 International License (http://creativecommons.org/licenses/by/4.0/), which permits use, sharing, adaptation, distribution and reproduction in any medium or format, as long as you give appropriate credit to the original author(s) and the source, provide a link to the Creative Commons license and indicate if changes were made.

The images or other third party material in this chapter are included in the chapter's Creative Commons license, unless indicated otherwise in a credit line to the material. If material is not included in the chapter's Creative Commons license and your intended use is not permitted by statutory regulation or exceeds the permitted use, you will need to obtain permission directly from the copyright holder.

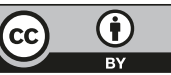

